\title{
SOURCE TO TAP URBAN WATER CYCLE MODELLING
}

\author{
Evangelos Rozos ${ }^{1}$ and Christos Makropoulos ${ }^{1}$ \\ ${ }^{1}$ School of Civil Engineering, National Technical University of Athens, Heroon Polytechneiou 5, \\ Athens, GR-157 80, Greece.
}

\begin{abstract}
The continuous expansion of urban areas is associated with increased water demand, both for domestic and non-domestic uses. To cover this additional demand, centralised infrastructure, such as water supply and distribution networks tend to become more and more complicated and are eventually over-extended with adverse effects on their reliability. To address this, there exist two main strategies: (a) Tools and algorithms are employed to optimise the operation of the external water supply system, in an effort to minimise risk of failure to cover the demand (either due to the limited availability of water resources or due to the limited capacity of the transmission system and treatment plants) and (b) demand management is employed to reduce the water demand per capita. Dedicated tools do exist to support the implementation of these two strategies separately. However, there is currently no tool capable of handling the complete urban water system, from source to tap, allowing for an investigation of these two strategies at the same time and thus exploring synergies between the two. This paper presents a new version of the UWOT model (Makropoulos et al., 2008), which adopts a metabolism modelling approach and is now capable of simulating the complete urban water cycle from source to tap and back again: the tool simulates the whole water supply network from the generation of demand at the household level to the water reservoirs and tracks wastewater generation from the household through the wastewater system and the treatment plants to the water bodies. UWOT functionality is demonstrated in the case of the water system of Athens and outputs are compared against the current operational tool used by the Water Company of Athens. Results are presented and discussed: The discussion highlights the conditions under which a single source-to-tap model is more advantageous than dedicated subsystem models.
\end{abstract}

Keywords: metabolism models, optimisation, urban water cycle, water demand management

\section{Introduction}

Increasing concerns about the impact of human activities on the environment, over the past decades, have led to the introduction of new guidelines (e.g. Sydney Water, 2011), treaties (e.g. Kyoto Protocol, 2011) and Directives (e.g. Directive 2000/60/EC, 2011) all of which directly affect the way we perceive and manage water and the environment. Within the urban water domain these concerns have motivated research inter alia on two separate but interlinked areas: supply management, related to optimal allocation and management of available water resources (ReVelle, 1999) and demand management focusing on reducing the requirements for potable water for domestic and industrial uses (Butler and Memon, 2006).

Supply management for urban water requirements typically includes the optimisation of the use/operation of 
several water sources, including reservoirs and/or boreholes (e.g. Vieira et al., 2011). The challenge here is to identify an operational strategy that ensures the optimum trade-off between risk of failure of the water supply system and operational costs. These objectives are often conflicting, since for example, pumping water (or desalination) may improve the reliability of the system (in terms of its potential to meet demands) but at the expense of high energy bills. Urban hydroinformatics provides the socio-technological tools and facilities for water professionals and stakeholders to implement integrated water resources management, and in particular to facilitate urban water systems (Gualtieri, 2011). A number of specialised models such as RIBASIM (RIBASIM, 2012), Hydronomeas (Koutsoyiannis et al, 2002) or GoldSim (GoldSim, 2011) have been developed to support the identification of the optimal strategies.

Demand management, on the other hand, can be achieved with the introduction of new water-aware, distributed technologies including low flush toilets or adoption of practices such as rainwater harvesting and water recycling (Makropoulos and Butler, 2010). Benefits from these technologies/practices cannot be easily estimated since they depend on interactions between these technologies and other appliances/technologies in the household as well as on climatic conditions. For example, the demand reduction from a rainwater harvesting scheme (with a given tank capacity) depends on rainfall depth, on the frequency of the rainfall events and on the number and the type of household appliances that can use harvested rainwater instead of potable (Rozos et al., 2010). To investigate such parameters and interactions, bottom up (micro-component based) models have been developed, that simulate the demand starting at the water appliance level. Such models are few, and include the Aquacycle model (Mitchel et al., 2001; Mitchell, 2005), the City Water Balance (CWB) model (Last and Mackay, 2010) as well as the Urban Water Optioneering Tool (UWOT) (Makropoulos et al., 2008). Since the purpose of these models is to estimate and/or forecast the water demand of an urban area, they simulate only the part of the urban water cycle that includes the distribution system, the consumption and the drainage of wastewater and stormwater. For a complete study of the urban water cycle, this demand has to be used as input to another tool, such as the supply management models mentioned previously.

In this paper the UWOT model was redesigned as an urban metabolism model (Minx et al., 2010) in order to be able to simulate both supply and demand side strategies and systems within a common (one-stop-shop) modelling environment. The new UWOT is able to simulate and optimise the complete urban water cycle (at the water balance level) including abstractions from the hydrosystem, operation of reservoirs, transmission of water, water treatment, distribution, water consumption at the appliance level, sewerage network and treatment and finally disposal to the water bodies, thus providing a common modelling environment for the whole urban water cycle from source to tap and back.

This holistic approach is consistent with the basic rationale behind the urban metabolism concept, which suggests that the relationship between the environment and an urban system can be described by systematically recording all flows to and from the environment (Minx et al., 2010). These flows include the typical urban water flows (potable water, stormwater and wastewater), but also the 'flows' related with the 
normal operation of the physical assets (pipe networks, pumping stations and treatment facilities) like required energy, materials and chemicals. Niza et al. (2009) have developed such a model at an aggregated level for Lisbon, Portugal. A more detailed model, although focused on energy-water nexus, has been developed by Venkatesh and Brattebo (2011) for Oslo, Norway. A new model capable of simulating every flow related to the urban metabolism is now under development as a deliverable of the working area 3 of the TRUST project (TRUST, 2012).

In this study, UWOT was tested in the particularly complex case of the urban water system of Athens, Greece, focusing also on the energy-water nexus. Athens, the Greek capital, is home to more than 3.1 million inhabitants, and is located in an arid part of the country. It is supplied by a complex multi-reservoir hydrosystem that also includes groundwater abstraction installations. The population is (slightly) rising for the last decade but reduces significantly during the summer. Per capita demand also exhibits significant seasonal variation. The complete urban water cycle was simulated using historical and synthetic rainfall timeseries and its performance was assessed using metrics related to water balance (abstractions from surface and aquifers, reservoir spills) as well as required energy and costs.

The paper starts with a description of the new UWOT, its conceptualisation and its approach to modelling the complete urban water cycle. The paper describes a novel parameterisation-simulation-optimisation approach and explains how UWOT implements it. The case study of Athens is then presented followed by the results of the application, their discussion and conclusions.

\section{Material and methods}

Source to tap modelling

Urban water models often use a hydraulics-based conceptualisation of the urban water network, simulating actual water flows, including runoff, potable water and wastewater. UWOT uses an alternative approach based on the generation, aggregation and transmission of a demand signal, starting from the household water appliances and moving towards the source (Rozos and Makropoulos, 2012; Rozos et al., 2010). This demand-oriented conceptualisation made it possible to expand the original UWOT's capabilities in order to simulate the whole urban water system from source to tap. The left panel of Figure 1 gives a simplified example of the water flows from the abstraction, through the transmission network to the treatment plant and then to the distribution network. Wastewater and runoff generated in the city are then collected in sewerage networks, treated and disposed to a surface water body. The right panel of Figure 1 shows the equivalent representation in UWOT. The upper part (inside the ellipse) includes abstractions, transmission and treatment of raw water (the external water system) whereas the lower part of this panel shows the generation of the demand and the disposal of wastewater and stormwater to water bodies (the internal water system). 

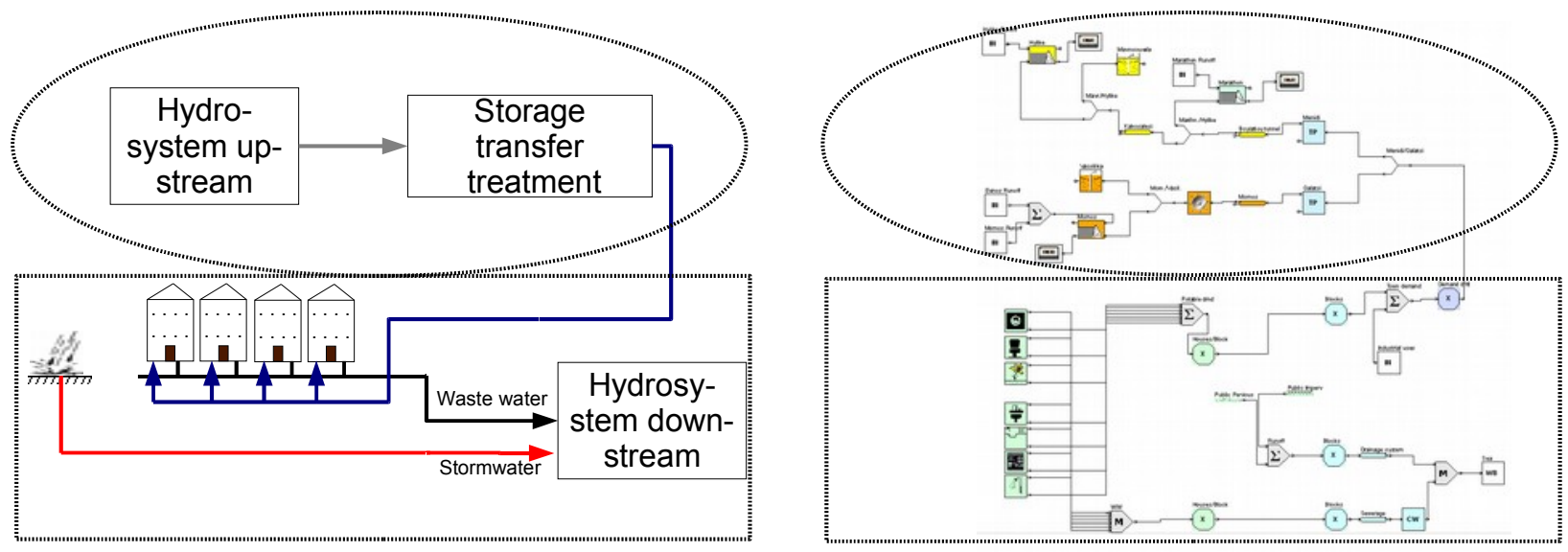

Figure 1: Left panel: abstract representation of the urban water cycle. Right panel: source-to-tap modelling of the complete urban water cycle with UWOT. Inside ellipses the water-supply system (see also Figure 8), inside rectangles the water consumption and the drainage system (see also Figure 9).

The two main parts of the UWOT model (the internal and the external water systems) are discussed in the following paragraphs. Additional details of specific functions and components are also given during the description of UWOT's implementation for the Athens water system.

\section{Modelling the internal water system}

UWOT's demand-oriented modelling concept will be further explained with the help of the simplistic hypothetical urban water network displayed in Figure 2.. The households of this figure include, for the sake of simplicity, only two water appliances: a shower and a toilet. The demand of both appliances, in this example, is assumed to be covered from rainwater stored in a local tank. This demand signal is symbolised with the elbow-arrow connections that start from the two appliances, are combined in the summation component (symbolised with " $\Sigma$ "), and is provided (the signal resulting from the summation) as input to the rainwater tank. The direction of a connection indicates which component emits the demand signal and which component receives it and delivers the requested demand. Demand signals comprise two numbers, the first gives the quantity of the demand in $\mathrm{L} / \mathrm{d} t$ (where $\mathrm{d} t$ is the simulation time step) and the second is an indication of the quality of the water flow, using BOD (in $\mathrm{mg} / \mathrm{L}$ ) as a metric.

The tank is filled by runoff from impervious areas in the household (e.g. from the roof) with rainfall timeseries being provided as inputs. If the mass balance of the tank indicates that the tank overflows, the tank spills excess water, which along with the water used in the toilet and the shower, are mixed in the component symbolised with "M", and disposed of, in this case, in a water body (WB). When the water inside the tank reaches a minimum level, the tank emits a demand signal for potable water from the centralised network, which, in this case, abstracts water from a borehole. The octagonal components (marked by "X") multiply the signals from a single household with the number of identical households in the simulated development. It can be observed that in this demand-oriented representation, the directions of the connections do not coincide necessarily with the directions of actual water flows. For example, the connections between appliances and 
tank have the opposite direction to the corresponding flows (i.e., the shower demand signal starts from the shower and ends at the tank whereas the response to this signal results in water flowing from the tank to the shower). Specifically, all the clean/raw water cycle connections have in UWOT, opposite direction to flows, whereas all the wastewater/stormwater cycle connections have the same direction to actual water flows; in other words, in UWOT, clean/raw water is demanded (pulled) while wastewater/stormwater is generated (pushed).

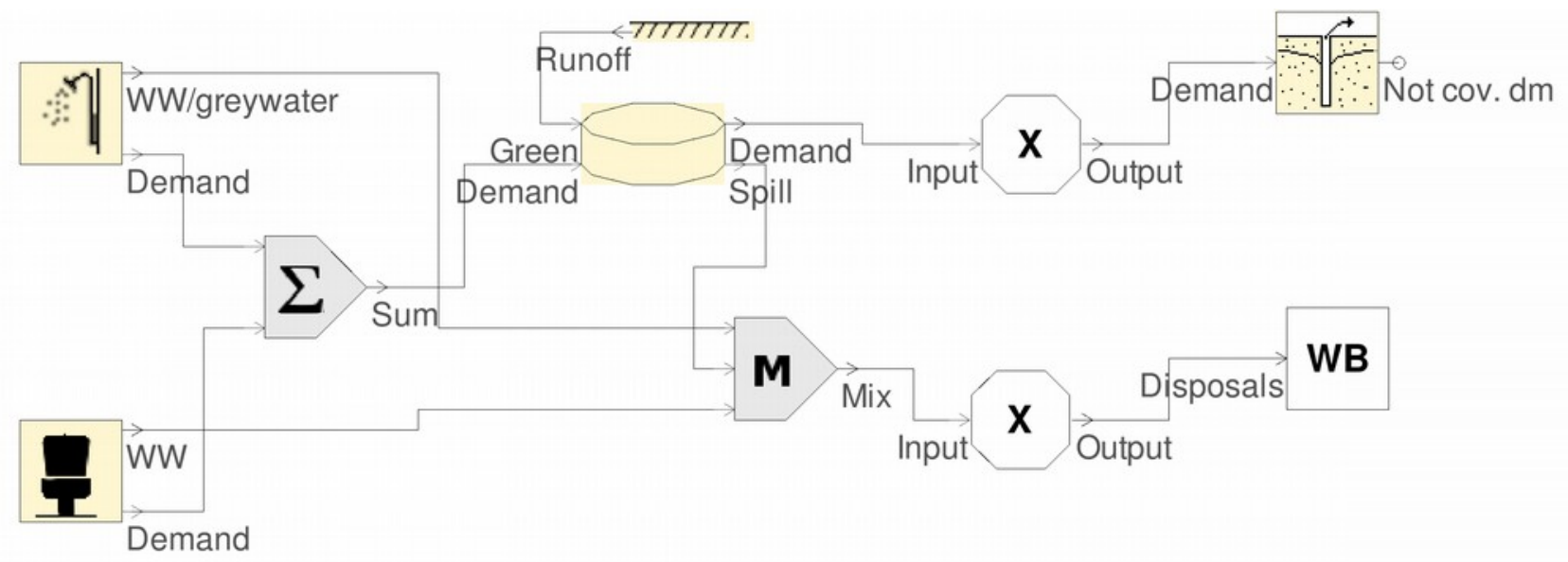

Figure 2: A simplified example of a water supply network representation in UWOT.

UWOT is also capable of providing an estimation of the water quality of the development's outflows (wastewater and runoff). To accomplish this, a BOD value is assigned to every connection that has the same direction with actual water flow. The values from multiple wastewater flows are combined (in the "M" component) assuming instant and full mixing, and conservative pollutants.

BOD for all connections that have opposite direction to the water flow is by default set to -1 (i.e. it is assumed that demand supplied meets the standards of quality regulations, be this for potable or reused water) The signals of these connections are combined by adding the quantitative part (in the " $\Sigma$ " components) and leaving the BOD equal to -1 .

The information required by UWOT to simulate the operation of water components (water consumption, required energy, BOD values, capital and operational cost, etc) is stored in a database which is called "technology library". The technology library is populated with information obtained from surveys, practitioner manuals, scientific publications, laboratory and pilot tests etc. This database allows combinations of specific technological options to be selected for evaluation by the user (Makropoulos et al., 2008). Originally, this was implemented using a spreadsheet, but in the UWOT version described in this paper, the technology library is implemented as a true relational database. The schema of this database is shown in Figure 3. The table Specification contains the values of the specifications of the components. The table 
SpecificationCategory contains the categories of specifications (e.g. "Energy", "Operational Cost", "Water usage"). The table Brand contains the available brands of all technologies (e.g. "Dual valve flush toilet", "Tap with aerator", "Shower cabinet", etc.). The table Unit contains the units of the specification values (e.g. "L", "L/use", "kWh/L", "pounds", etc.). And finally, the table Technology contains the available technologies (e.g. "Bath", "Washing machine", "Aqueduct", "Local tank", "Reservoir", etc) and, for household appliances, their average frequency-of-use (in uses per person per day). The relational database management system used is SQLite. The user can therefore decide to include a specific technology in the household (e.g. a toilet flush) and select a specific type of toilet flush (e.g. a dual valve flush) with a specific water usage (e.g. $6 \mathrm{~L} /$ use) and estimate its performance, making setup and testing new technological options, both generic (at the design stage) and detailed (at the simulation stage). This approach offers itself to both evaluation of predefined technological configurations and optimisation for best options identification (Makropoulos et al., 2008).

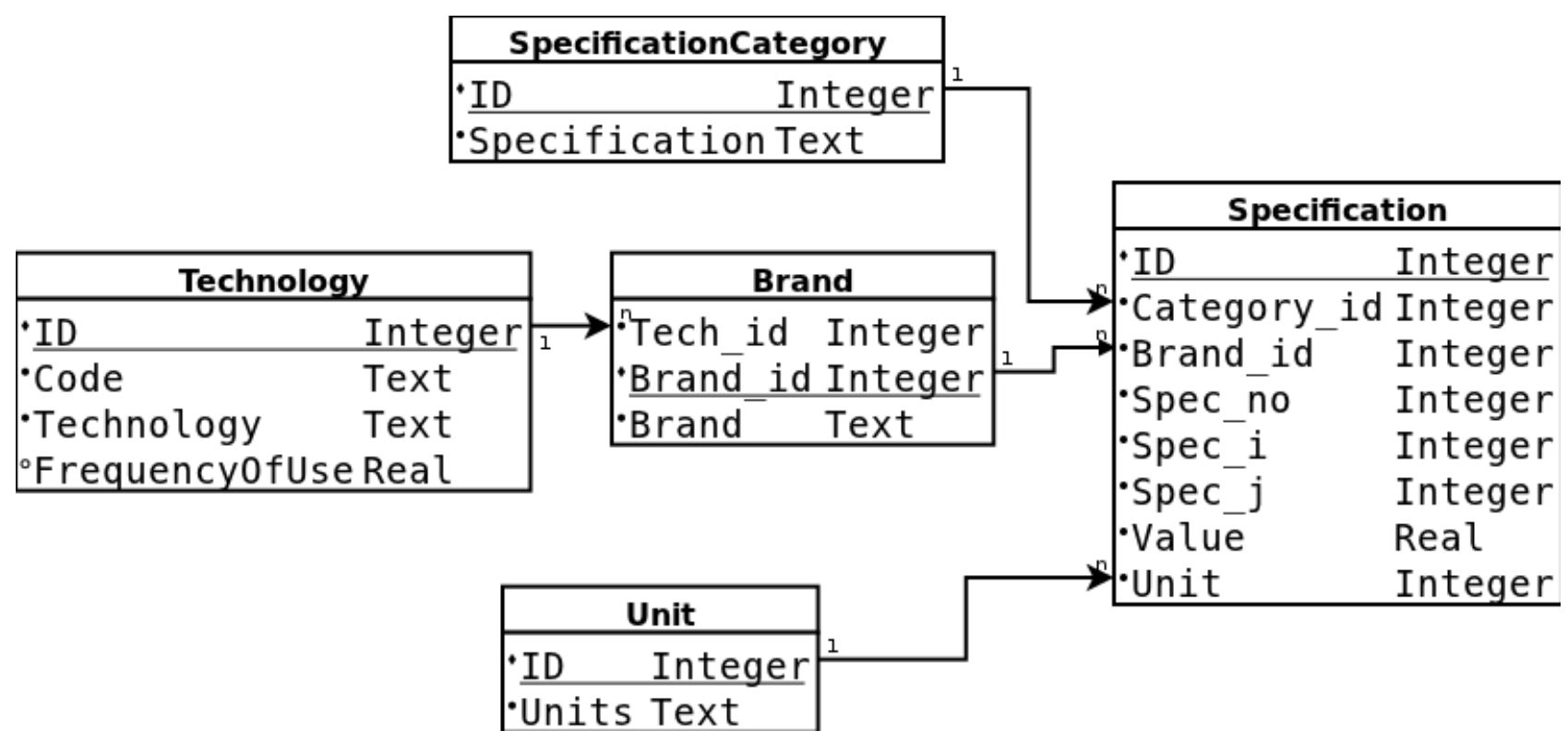

Figure 3: Schema of the technology library database.

The UWOT engine is written in C and takes advantage of the Matlab MEX API (MathWorks, 2011) that wraps the engine into a Matlab function (called mxUWOT) for use with Matlab's advanced optimisation algorithms (Figure 4). The mxUWOT needs two matrices to simulate a given urban water system configuration: a list of the system's components (from appliances to reservoirs) and a list of the connections between them, defining the system topology. 


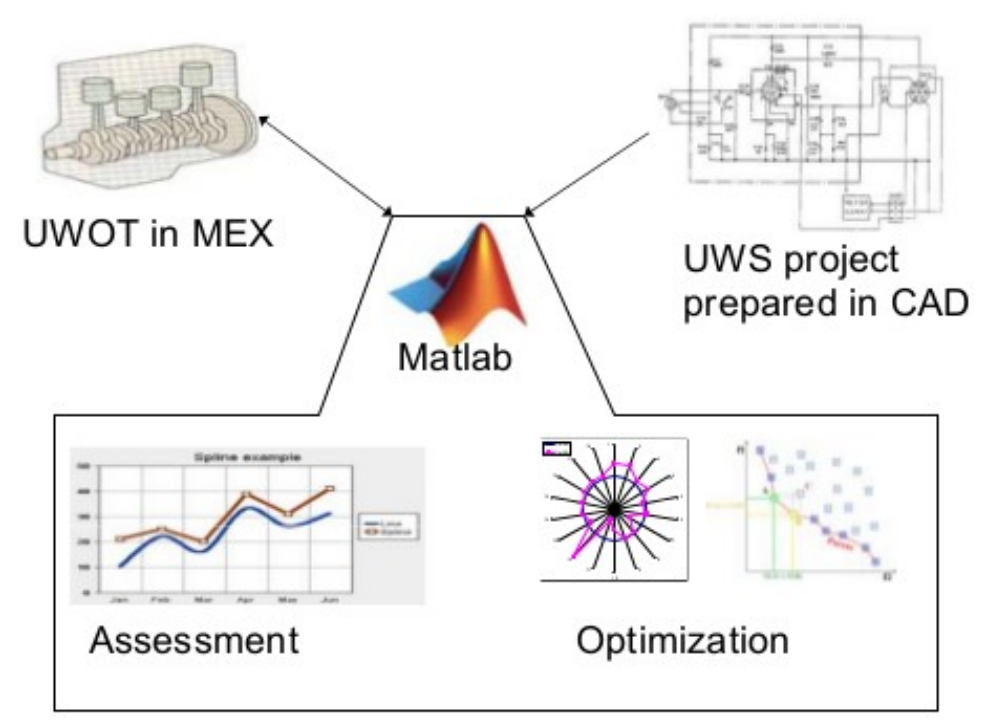

Figure 4: Schematic of Matlab-UWOT coupling.

A custom CAD application was developed using Python 2.7 and PyQt 4.8 as a graphical user interface (Figure 5), allowing the user to define this topology using usual drag-and-drop and point-and-click functions. First, the user inserts in the drawing area the components of the network by clicking on the corresponding buttons of the Components Toolbar. Then, the user defines the connections between these components with the point-and-click method. This provides the flexibility to define any urban water cycle network including conventional water supply or water recycling schemes, combined or separate wastewater systems, one household type or multiple household types, etc. Also, the user can choose to model either a part of the urban water cycle, if he wishes to focus only on the inputs and outputs of this part, or the complete urban water cycle (like in the case study presented here). When the design is completed, the GUI automatically generates as xml files the two matrices required as arguments of mxUWOT. Further than these matrices mxUWOT also needs:

- the specifications of the installed components, i.e. appliances/technologies. These are extracted from the technology library.

- timeseries of rainfall (to provide the input to reservoirs, rainwater harvesting schemes as well as urban runoff)

- timeseries of occupancy (to account for seasonal variations of population)

- timeseries of numbers of households (to account for urbanisation)

- frequency-of-use of the household appliances: although a constant value of the frequency of use of each appliance is included in the technology library the user is allowed to define timeseries of frequency-of-use as well, to enable simulation of changes in behaviour.

This information is passed as arguments to mxUWOT, which then runs the simulation. The results of the 
simulation returned by mxUWOT are timeseries, which are classified into two categories:

(i) The first one includes the timeseries whose values directly influence the operation of the urban water cycle, i.e.: (a) the demand signals emitted by any component (e.g. water demand, runoff, waste water, etc); and (b) the amount of water stored inside tanks, stored as soil moisture in pervious areas, stored inside ponds as part of SUDS solutions, etc.

(ii) The second category includes timeseries of: (a) abstract indicators like reliability, risk, etc; (b) water that exits the urban water cycle upstream of a nominal outlet (e.g. leaks, evaporation, infiltration, etc); and (c) the use of non-water resources required for the operation of the urban water cycle (e.g. energy, money).

UWOT uses two types of virtual components to record these two types of timeseries, the "loggers" and the "pots" respectively. The loggers can be considered as hypothetical measuring devices that can be fitted in any place of the network to measure and log the signals passing through them (e.g. a logger can be connected with a reservoir to log the overflows). The pots can be considered as accounting devices that log non-water resources consumed by a set of components belonging to the same group (e.g. the energy consumed by in-house water appliances).

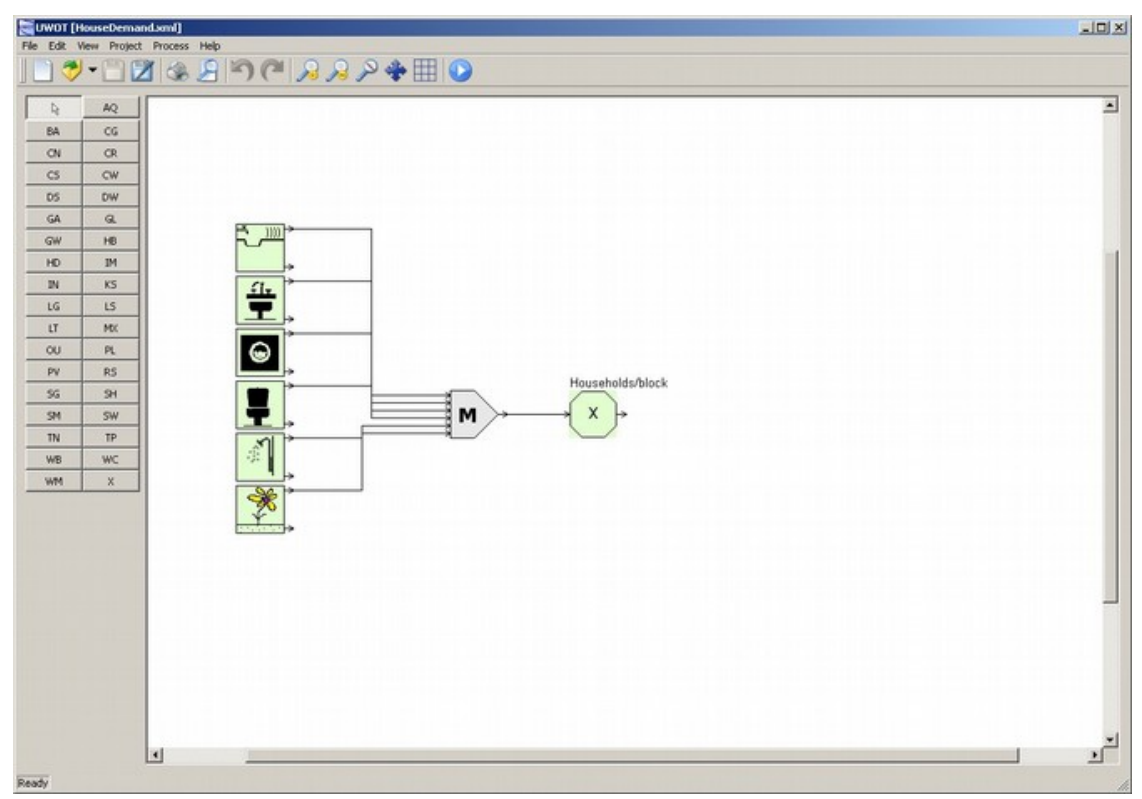

Figure 5: UWOT CAD application.

\section{Modelling the external water system}

The supply management problem is often referred in the literature as "optimal control of reservoir systems". It consists of deciding at each time step how to cover multiple demands using multiple water sources. A common method to study this kind of problem is stochastic dynamic programming (e.g. Su and Deinenger, 1972). This method has the disadvantage that it requires a large number of control variables, typically the sequences of releases from all reservoirs and for all time steps of the control period. Motivated by this 
disadvantage, Nalbantis and Koutsoyiannis (1997) recommended an alternative method, the parameterisation-simulation-optimisation (PSO) approach. This method uses a handful of control variables, which are parameters of a simple rule. This rule, referred to hereafter as parametric rule, is considered valid for the entire control period and determines the releases from different reservoirs at each time step. The PSO method employs the following simple parametric rule for the optimal control problem. Suppose $V$ is the total storage (i.e. the total amount of water stored) in the studied system at the end of the period of interest. Then, the target storage at each reservoir (i.e. the water that would be stored at each reservoir if the system was run in an optimal way) is $S^{*}=a_{i}+b_{i} V$, where $a_{i}$ and $b_{i}$ are unknown parameters to be optimised and $i$ is $\left\{1, \ldots, N^{\prime}\right\}$ where $N$ 'is the number of reservoirs. With this technique the dimensionality of the parameterisation is $2 N^{\prime}$ regardless of the number of time steps. These parameters can be easily optimised with a global optimisation algorithm. Koutsoyiannis et al. (2002) combined this method with a diagraph representation of the natural and artificial hydrosystem to allocate the flows (i.e. simulate flows into the artificial and natural hydrosystem) between the locations of demand and the locations of supply (i.e. the releases from reservoirs). They implemented these ideas in an application called Hydronomeas (Hydronomeas, 2012) which is currently used by the Water Company of Athens (EYDAP) to operate their hydrosystem.

In UWOT, the PSO approach, with a formulation appropriate to its demand-oriented design, is used for optimizing the operation of the external water supply system. To explain this formulation the operation of an important UWOT component of the external water system, the "splitter", needs to be described first. Figure 6 displays an example where the water demand of a development is covered using the releases from two reservoirs. Demand signals emitted from the development pass through the splitter, which distributes the incoming demand signal to two outputs. This distribution is regulated by a parameter that gives the percentage of incoming demand redirected to the first output of the splitter (with the rest of the incoming demand being redirected to the other output).

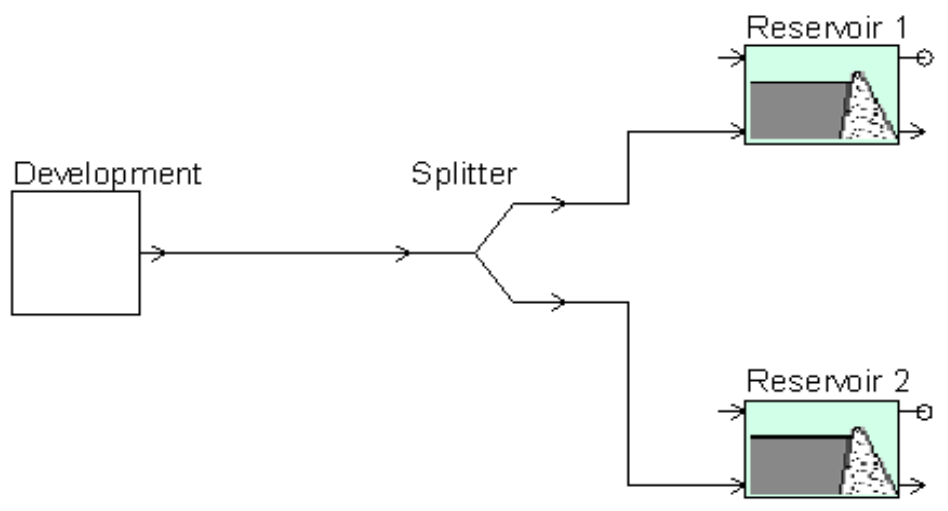

Figure 6: Simplified example demonstrating the operation of a splitter.

A water supply system with $N$ sources of water (of which $N^{\prime}$ are reservoirs and the rest are for example boreholes or desalination plants) connected in the simplest possible way (i.e. with only one route connecting 
each system component to each other) requires $N-1$ splitters. At any given time step, $N-1$ parameters are therefore required to describe the operation of the system. Unfortunately, these parameters (that define how demand is distributed to the various water resources) are not constants but should in principle change according to water availability in the water sources. An attempt to directly optimise these parameters would result in a high-dimensional problem. To avoid this, the parameters of the splitters are estimated indirectly from the water storage of the $N^{\prime}$ reservoirs based on a $(N-1) \times N^{\prime}$ matrix symbolised with $\mathbf{C M}$ and a vector $\boldsymbol{a}$ with $N-1$ elements. If $\boldsymbol{p}$ is the vector with the splitter parameters $p_{j}$ at the time step $t$ of simulation, where $j$ is $\{1 \ldots N-1\}, \boldsymbol{s}$ the vector with the reservoir storages $S_{i}$ at the time step $t$ of simulation, where $i$ is $\left\{1 \ldots N^{\prime}\right\}$, and $\boldsymbol{K}$ the $N^{\prime} \times N^{\prime}$ diagonal matrix of which elements are the reservoir capacities, then at every time step the parameters of the splitters are calculated using the following formula:

$\boldsymbol{p}^{\mathrm{T}}=\mathbf{C M}\left(\boldsymbol{s} \boldsymbol{K}^{-1}\right)^{\mathrm{T}}+\boldsymbol{a}^{\mathrm{T}}$

The previous equation has the same form with the formula of multiple linear regression (Papoulis, 1999). If (1) was a multiple regression formula then $p_{\mathrm{i}}$ would be the response variables, $S_{i} / K_{i}$ the explanatory variables, the elements of $\mathbf{C M}$ would be the regression coefficients and the elements of $\boldsymbol{a}$ would be the error term or the value of the response variables when the explanatory variables are 0 .

For example, the $\mathbf{C M}$ matrix of the simplified water supply system shown in Figure 6 would be $\left[c_{1} c_{2}\right]$ (a matrix with one row for the single splitter and two columns for the two reservoirs). The vector $\boldsymbol{a}$ would be [a] (one element for the single splitter). If $S_{1}$ and $S_{2}$ were the storages of reservoirs 1 and 2 at each time step and $K_{1}$ and $K_{2}$ their capacities then, after substituting to (1), at each time step the coefficient of the splitter would be calculated by the formula: $c_{1} S_{1} / K_{1}+c_{2} S_{2} / K_{2}+a$. If a third reservoir was added to Figure 6 then a second splitter would have been required and then the $\mathbf{C M}$ matrix would become $2 \times 3$ and the vector $\boldsymbol{a}$ would have two elements. The result of the substitution to (1) would then be a vector of two elements (more specifically $\left.\left[c_{11} S_{1} / K_{1}+c_{12} S_{2} / K_{2}+c_{13} S_{3} / K_{3}+a_{1} \quad c_{21} S_{1} / K_{1}+c_{22} S_{2} / K_{2}+c_{23} S_{3} / K_{3}+a_{2}\right]\right)$ with these two elements being the coefficients of the two splitters at each time step.

From the previous it is inferred that the dimensionality of a water supply system with $N$ sources, of which the $N^{\prime}$ are reservoirs, is $(N-1)\left(N^{\prime}+1\right)$. However, in some cases, as will be demonstrated in the case study, the dimensionality can be further reduced using reasonable assumptions about the values of $\mathbf{C M}$ that are dictated either from good management choices or from negligible sensitivity of some parameters to the water stored in some reservoirs.

\section{The case of Athens}

\section{The multi-reservoir system of Athens}

The Athens external water supply system (Figure 7) is an extensive and complex hydrosystem that extends over an area of around $4000 \mathrm{~km}^{2}$ and includes surface as well as groundwater sources. It incorporates four reservoirs, four Water Treatment Plants, $350 \mathrm{~km}$ of main aqueducts, 15 pumping stations and 100 boreholes 
(Kozanis et al., 2012). The system is run by the Athens Water Supply and Sewerage Company (EYDAP). The overall storage capacity of the hydrosystem approaches $1400 \mathrm{hm}^{3}$, but just two of the reservoirs, the Mornos reservoir and the natural lake Hylike, hold 88.5\% of it. Although Evinos reservoir (in operation since the summer of 2001) has comparatively small capacity, it receives the largest inflows among all four reservoirs. Water from Evinos is diverted through a tunnel and stored in the neighbouring Mornos reservoir (Efstratiadis et al., 2004).

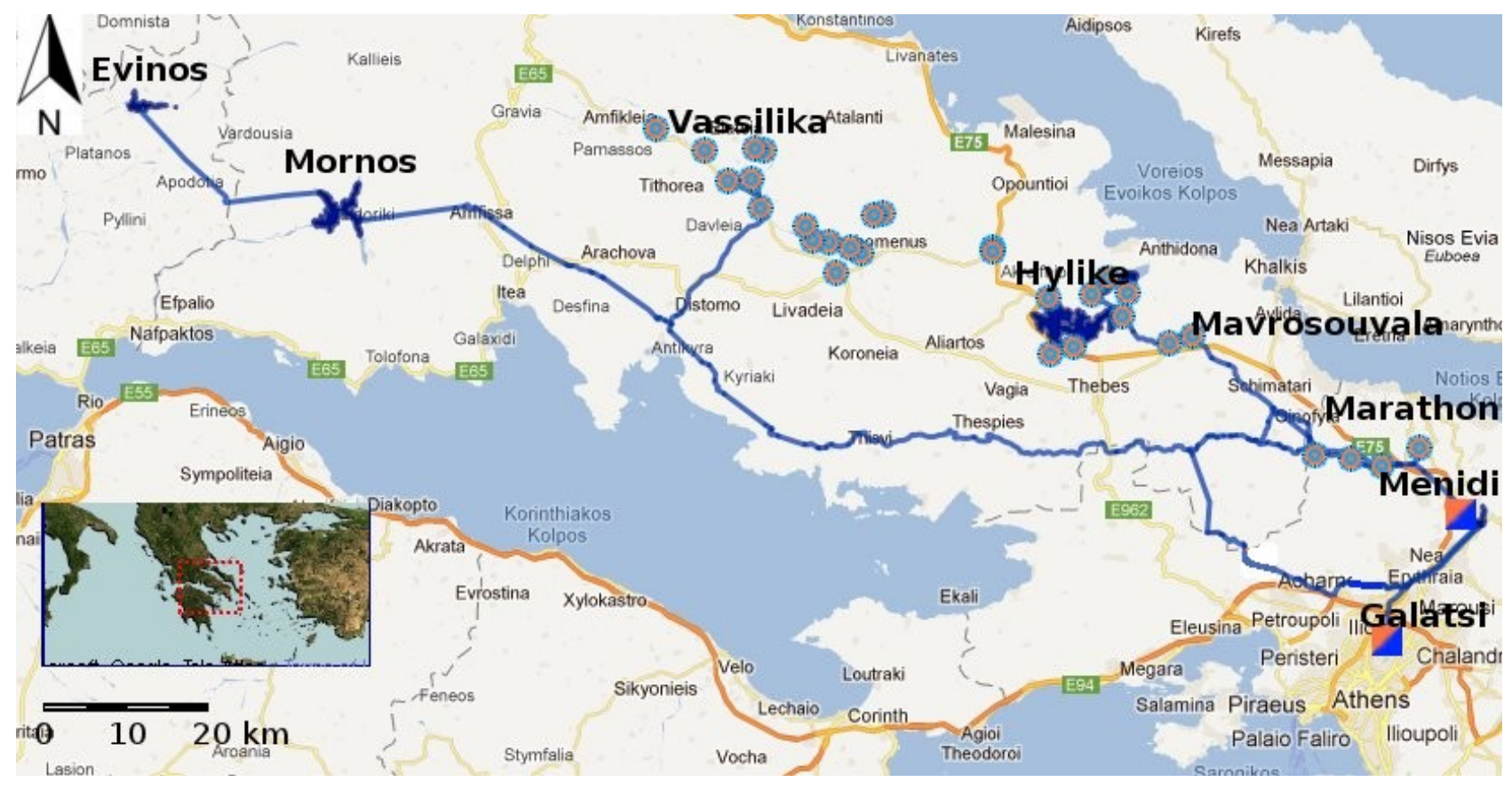

Figure 7: Athens external water supply system comprises the Evinos, Mornos, Hylike and Marathon reservoirs, the Vassilika and Mavrosouvala boreholes, and the Menidi and Galatsi treatment plants.

The water supply network has two principal branches. The north branch carries water from Hylike, Mavrosouvala boreholes and Marathon reservoir. Some parts of this branch require energy for water pumping. The bottom of Hylike is karstified resulting in significant leakages that decrease with the water level in the lake (Katerinopoulou et al., 2009). Therefore, even though the use of water from this reservoir is not attractive from economic point of view, it is imperative in cases of water shortage to use as much water as possible from this reservoir to keep the level, and consequently the leakages, low. The south branch carries water from Mornos reservoir and Vassilika boreholes. The water is flowing by gravity in the aqueducts of this branch. Furthermore, elevation-drops at some locations along this branch are exploited for energy production. 


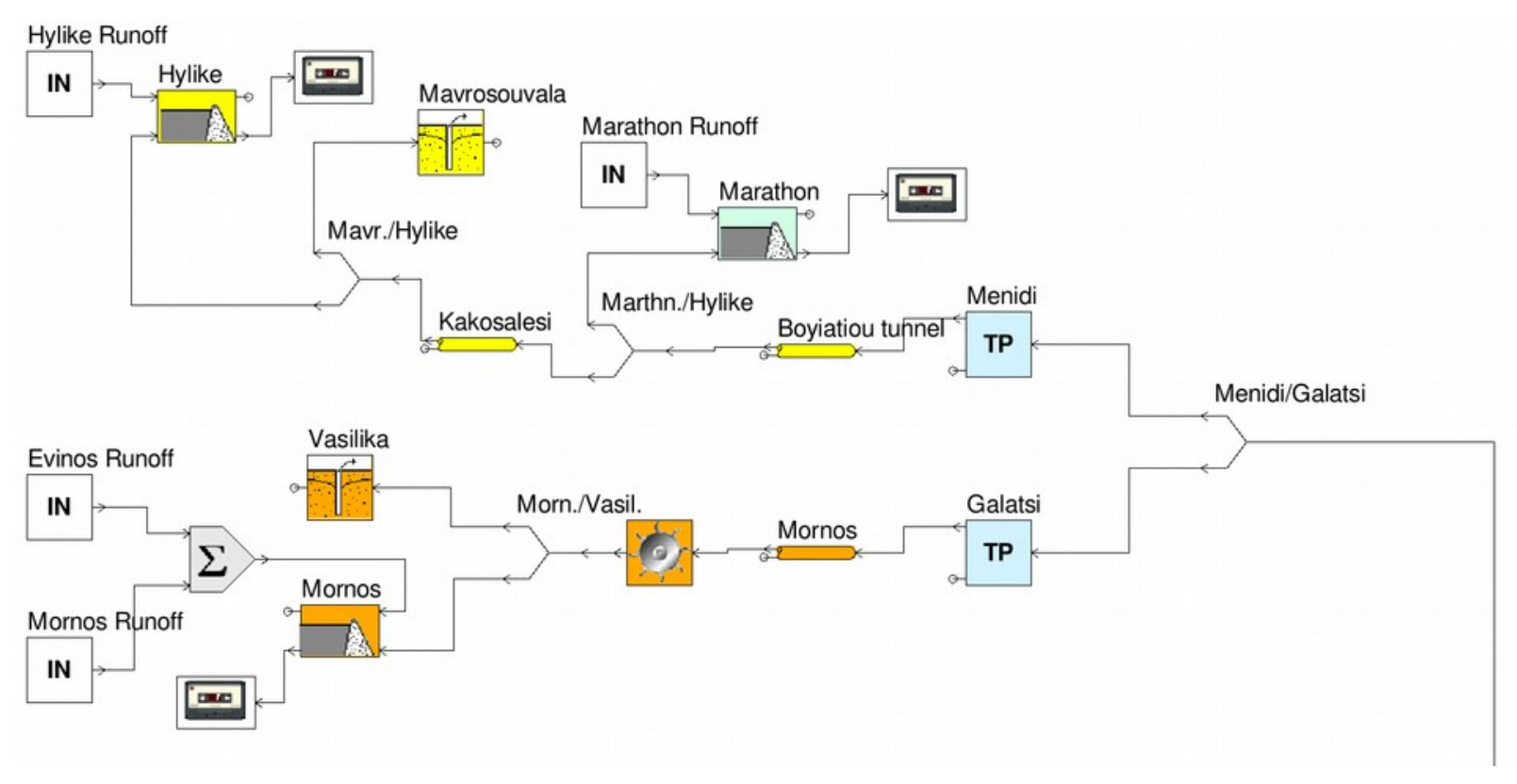

Figure 8: Representation of Athens external water supply system in UWOT.

Figure 8 displays UWOT's representation of the external water supply system of Athens. Some simplifications were introduced in the schematisation to reduce the complexity of the supply network without compromising model accuracy. Specifically: (i) Simulation of the Evinos reservoir was omitted because of its small capacity compared to its inflows (the Evinos dam was actually considered a diversion of Evinos river to Mornos reservoir). To simulate this, the runoff from the catchment area of Evinos was added to the runoff from the catchment area of Mornos and the capacity of the component that represents Mornos was augmented appropriately to include the capacity of the Evinos reservoir. (ii) Only the two larger WTP (Menidi and Galatsi) were included in the schematisation. (iii) Loops in the supply network, i.e. redundant routes for backup in case of failures, were not modelled.

The schematic representation of the Athens external water supply system (Figure 8) employs the following UWOT components:

- The components labelled "IN" are used to "INsert" into the network timeseries of demand signals. For example, the component with the caption "Hylike Runoff" (uppermost left) inserts into the network the demand to drain the runoff generated in the Hylike catchment area.

- The components symbolised with an icon of a dam, simulate reservoirs. These components take into account the capacity of the reservoir and the incoming flow (more precisely the demand to drain water from an upstream component) to simulate the fluctuation of storage and overflows. Leakages are assumed proportional to the water level inside reservoirs. The latter is estimated from the storage using a second order polynomial equation.

- The components symbolised with a tape are loggers. For example, the logger connected with the spill 
output port of Hylike logs overflows from the reservoir. Loggers can be inserted by the user during the design of the water system, at any point to monitor demand signals. Loggers are also inserted automatically by the CAD application hard linked to some components (see description of aqueducts and WTP components).

- The thin horizontally-placed cylindrical components represent aqueducts. These components take into account the capacity of the aqueduct and water losses (as percentage of incoming demand). If pumps are used, then the required energy is estimated by multiplying the incoming demand (up to the capacity) with the energy consumption per unit volume. If the incoming demand exceeds the capacity, the exceedance is recorded into the dedicated logger of this component.

- Hydroturbines are represented with the component whose symbol resembles a wheel with spikes. The energy produced at hydroturbines is estimated by multiplying the incoming demand with the energy per unit volume.

- The components with "TP" represent WTP. The treatment plants require energy for their operation, which is estimated by multiplying the incoming demand (up to the capacity) with the energy consumption per unit volume. If the incoming demand exceeds the capacity, the exceedance is recorded into the dedicated logger of this component.

Pots are also employed, though not visible in Figure 8, to record the timeseries of leakages in the aqueducts, timeseries of infiltration (in Hylike) abstractions from the aquifers (boreholes) and energy (e.g. energy required to pump water in the Hylike aqueduct, to pump water from boreholes, to treat water, etc).

Since the Athens water supply network has 5 principal water sources (Evinos along with Mornos, Hylike and Marathon reservoirs, and Mavrosouvala and Vassilika boreholes) from which 3 are reservoirs (i.e. $N=5$ and $\left.N^{\prime}=3\right)$, the representation of the network employs four splitters $(N-1)$ : Menidi-Galatsi, Marathon-Hylike, Mavrosouvala-Hylike, Mornos-Vassilika (Figure 8).

\section{Domestic and industrial demand of the case study}

Although UWOT can be used to represent multiple household types, as presented for example in Rozos et al. (2011) where four different household types were simulated to obtain spatially distributed estimations of potable water demand, wastewater and runoff discharges, in this case study, only one household type (with characteristics that correspond to the average household type for Athens) was used to represent the whole city. This simplification is justified here because water demand is required at only one point, the Menidi/Galatsi splitter (rightmost splitter in Figure 8).

Figure 9 displays the representation in UWOT of the Athens internal water system. UWOT estimates the water demand of each household appliance by multiplying the average consumption per household appliance (taken from EEA (2001) and Grant (2006)) with the frequency-of-use (average values taken from Grant (2006)). If the frequency-of-use is not constant (as is the case here) then timeseries, with a time step equal to 
time step of simulation, should be provided.

The outputs of all appliances are aggregated up to the level of a household using the components of summation (symbolised with " $\Sigma$ ") and mixed (symbolised with "M") as discussed earlier. A second level of aggregation, up to the level of urban blocks, is accomplished with the octagonal component "X" that multiplies the quantitative part of the household demand signal with the number of households per block. In this case study, the term "household" was used as a generic term that includes any type of residential unit (e.g. actual households or blocks of flats) with a single connection to the water mains. A final aggregation follows (octagonal components named "Blocks" and "Public uses") to give the domestic demands at the scale of a town that includes also the water supplied for public uses. Demands for industry are introduced at this scale using the component "IN" to insert into the network timeseries of demand calculated externally. Domestic, public and industrial demands are summed to give the total demands of the town. This multilevel aggregation allows UWOT to assess separately two urban characteristics: density and sprawl. The former can be represented with the occupancy or the number of households per block, and the latter with the number of blocks.

The components that represent sewerage and drainage operate like the aqueduct components. If the incoming demand exceeds the capacity of the sewerage and drainage network, then the exceedance (overflowing volume of storm or wastewater) is logged at a dedicated logger. In case of combined sewers this amount represents the combined sewer overflow (CSO). The overflow volume can serve as an indication of flood risk.

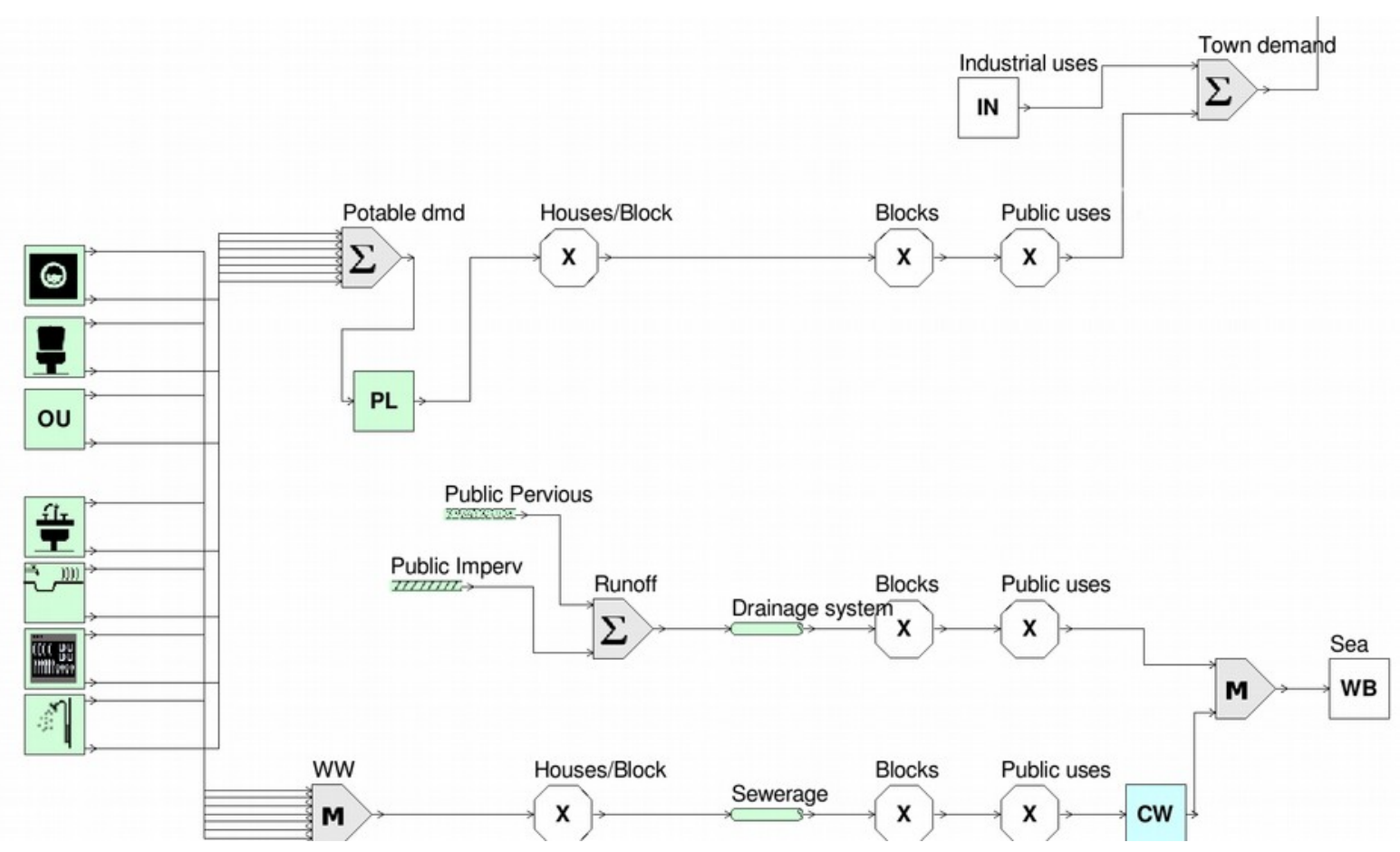

Figure 9: Simplified representation of Athens internal water system in UWOT. 


\section{Timeseries and data of the external water system}

The capacities of the three reservoirs, Evinos plus Mornos, Hylike and Marathon, are $904 \mathrm{hm}^{3}, 595 \mathrm{hm}^{3}$ and $43 \mathrm{hm}^{3}$ (the dead volumes are 159, 12 and $9 \mathrm{hm}^{3}$ respectively). The average annual inflows of Evinos, Mornos, Hylike, and Marathon are 274.1, 233.6, 267.9 and $18.7 \mathrm{hm}^{3}$ respectively. Historic timeseries of inflows to these four reservoirs were obtained from Mamasis et al. (2011). These timeseries have a monthly time step (which was also selected as the time step of simulation) starting on the 1st of January of 1996 and ending on the 1st of September of 2010.

\section{Timeseries and data of the internal water system}

Unfortunately, monthly timeseries of population and frequency-of-use were not available for Athens. The only available data for the inner water system were timeseries of total demand at the WTPs, the average population served annually and the distribution of demand to domestic and public uses. The latter is $35 \%$ of the total demand for Athens with insignificant seasonal fluctuation (Efstratiadis et al., 2009).

To overcome this lack of data, reconstructed timeseries of population and frequency-of-use were used instead. The reconstructions were made using reasonable assumptions whose plausibility was verified by the goodness of fit of the estimated demand to the historical data. The reconstructed timeseries should not however be considered reliable estimations of the actual historical values since alternative reconstructions could plausibly result in equivalently good fits. However, this is not a major concern in this study, whose purpose is to demonstrate UWOT's potential for source to tap simulation.

For the reconstruction of population timeseries two patterns of fluctuation were assumed:

- The first pattern is a predefined periodic fluctuation that reflects temporary population reductions due to summer vacations. Population reduces to $90 \%$ and $95 \%$ of the maximum during August and September respectively. This was implemented by reducing the occupancy to 10.7 and 11.3 for August and September respectively, and returning to the maximum value, which is 11.9 (ELSTAT, 2012), for the rest of the year.

- The second pattern is a linear increase of the population from 3.120 million to 3.260 million from 2001 to 2010 (Efstratiadis et al., 2009). This was implemented by increasing the number of urban blocks from 21952 to 22950 (octagonal components named "Blocks" in Figure 9). The number of households per block (octagonal components named "Houses/Block" in Figure 9) was kept constant and, in this case, equal to 12 during the whole simulation (this number is consistent with the average number of buildings per block appearing in the orthophoto images of Athens as discussed in Rozos et al. (2011)).

For the reconstruction of the frequency-of-use timeseries the following two patterns were assumed:

- The first pattern is a seasonal variation, which can be attributed to the fact that the higher temperatures during the warm period of the year result in more frequent use of some appliances. For this reason, the 
frequency-of-use of washing machines, showers and outside uses (including gardening) was assumed to vary following the pattern displayed in Figure 10. For example, the frequency-of-use of washing machines during the cold period was assumed to be $75 \%$ of the average frequency-of-use whereas the frequency-of-use during the warm period is $145 \%$ of the average value. The same applies for shower and outside uses. In the same chart, the frequency-of-use of toilets (provided for comparison), is assumed not to be influenced by temperature, and is represented by a flat line at $100 \%$ of the average value.

- The second pattern is shown in Figure 11. This corresponds to an increasing trend in per capita consumption that is being observed since 1996 and could be attributed to socio-economic drivers. Figure 11 displays the relative annual consumption (annual consumption divided by the average consumption of the 1996-2010 period) from 1/1/1996 to 1/10/2010. The historical values are plotted with dots and the continuous line represents an exponential fit to the historical data. The formula of the fit is 147.7 $\exp (-0.001405 x)-73.64 \exp (-0.01174 x)$ where $x$ is the number of the month starting from 1 for January 1996 and ending at 177 for September 2010.

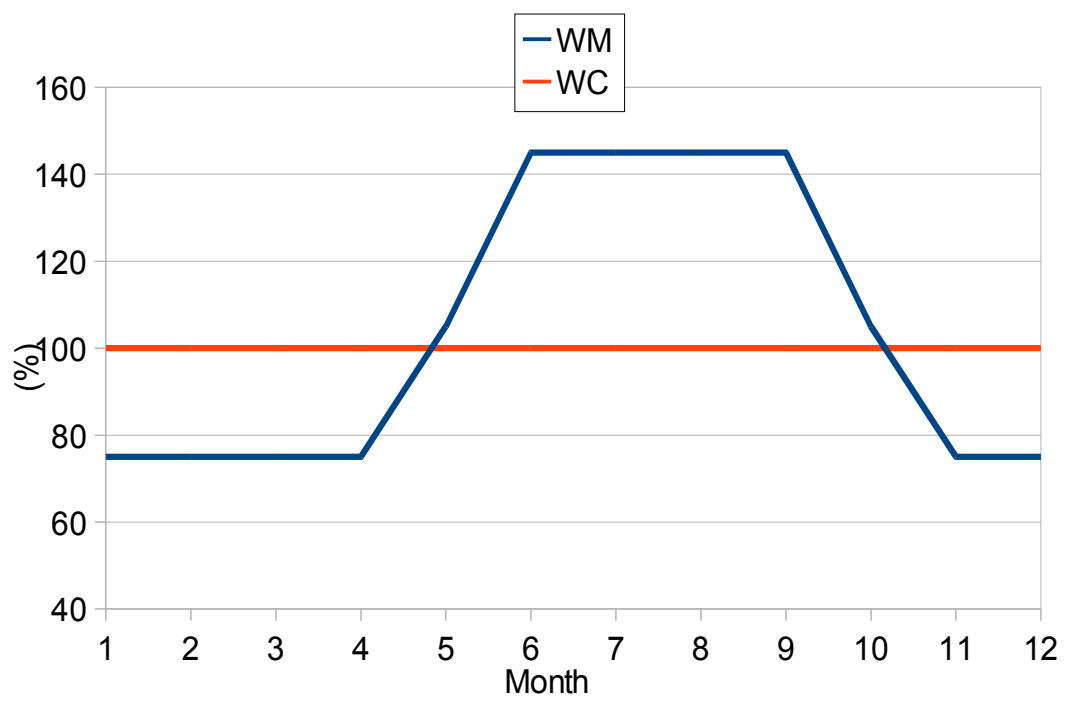

Figure 10: Seasonal variation of frequency-of-use of Washing Machine (WM) and toilet (WC). 


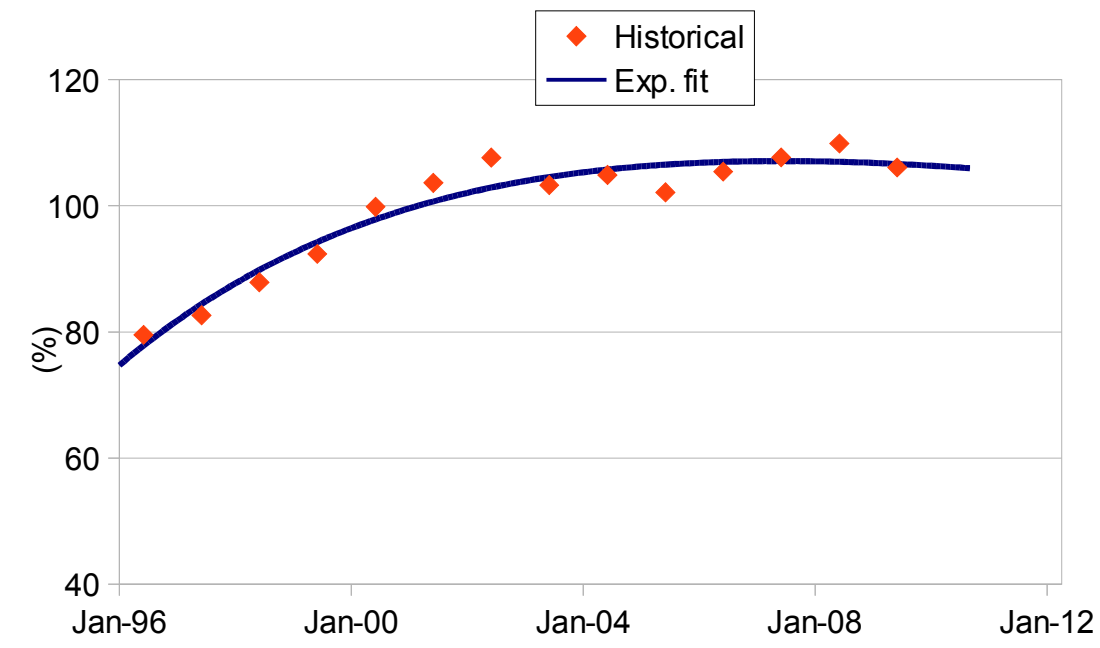

Figure 11: Historical values of relative annual consumption and exponential fit.

\section{Optimisation of the water supply system}

UWOT was used to optimise the water supply system operation: the target of the optimisation was to identify the optimum parametric rule for the external water supply system that minimises the average annual supply deficit to cover demand (as calculated dynamically by the simulation of the internal water system) along with the minimisation of the required energy. Synthetic timeseries of 100 years were created for all relevant UWOT inputs and used in the optimisation process. Specifically, synthetic inflows to the reservoirs were produced from the historical timeseries of the external water supply system using the stochastic model Castalia (Castalia, 2012). Castalia includes procedures for simulation of the long-term hydrologic persistence of multivariate processes on annual scale, and cyclostationary (periodic) stochastic models and disaggregation procedures for the simulation on monthly scale (Koutsoyiannis, 2001). For the generation of synthetic timeseries of water demand, the average population served annually and the average annual values of frequency-of-use were considered constant and equal to the last year of the historical timeseries. The use of synthetic timeseries ensures that the parametric rule developed is robust against main source of uncertainty - for example climatic variations.

The objective function used in the optimisation was the weighted summation of: (i) failure to cover the demand (either due to water deficit in the reservoirs, or due to exceedance of the capacity of transmission and treatment components) and (ii) the consumed energy (for water pumping from boreholes and Hylike reservoir) for the entire 100 years simulation period. The failure (deficit) was expressed in $\mathrm{hm}^{3}$ of average annual deficit and the energy in GWh of average annual consumption. The optimised parameters were the elements of the matrix $\mathbf{C M}$ and the vector $\boldsymbol{a}$ (see equation 1). The optimisation algorithm used was the Shuffled Complex Evolution algorithm (Duan et al., 1992). Nine parameters $\left(c_{1} \ldots c_{9}\right)$ were used to parameterise the operation of the water supply system. The first five parameters were elements of $\mathbf{C M}$ whereas the last four were the elements of vector $\boldsymbol{a}$. 
The positions the parameters $c_{1} \ldots c_{5}$ hold in the $\mathbf{C M}$ matrix are shown in Table 1. For example, the position $(1,1)$, which is occupied by $c_{1}$, corresponds to the coefficient that relates Mornos storage to the value of the parameter of the Menidi-Galatsi splitter.

Table 1: CM matrix for the optimisation of Athens external water supply system.

\begin{tabular}{lllll}
\hline & Mornos & $\begin{array}{l}\text { Hylike plus } \\
\text { Marathon }\end{array}$ & Hylike & Marathon \\
Menidi-Galatsi splitter & $c_{1}$ & $c_{2}$ & 0 & 0 \\
Mavrosouvala-Hylike splitter & 0 & 0 & $c_{3}$ & 0 \\
Mornos-Vassilika splitter & $c_{4}$ & 0 & 0 & 0 \\
Marathon-Hylike splitter & 0 & 0 & 0 & $c_{5}$ \\
\hline
\end{tabular}

For the parameterisation, it was assumed that the distribution of a demand signal in a splitter depends only on the storage of the reservoirs downstream (from the demand point of view) of this splitter. For example, the distribution of the Athens demand between north and south branches depends on the storage of all reservoirs, but the distribution of the demand signal between Hylike and Marathon (see Marathon-Hylike splitter in Figure 8) should depend only on the storage of Hylike and Marathon and not on the storage of Mornos.

Since the decision of how to distribute the demand of Athens to the two branches depends on the total storage of each one these two branches, an extra column was inserted in $\mathbf{C M}$ to combine the two separate parameters (one for Hylike and one for Marathon) into a single one. Furthermore, the parameter that relates Hylike storage to the distribution of demand between Hylike and Marathon (Marathon-Hylike splitter) was dropped. This simplification is justified by the fact that Marathon is not a critical component in the long-term planning of Athens water supply system due to its small capacity, and is considered a supportive source. These assumptions resulted in a sparse $\mathbf{C M}$ matrix and a parameterisation with low dimensionality.

For comparison purposes, the Hydronomeas model was also used to optimise and simulate the external water supply system (see Figure 12). The same synthetic timeseries of reservoir inflows and the demand estimated by UWOT were used as inputs. The optimisation tool integrated into Hydronomeas was used to estimate the parameters $a$ and $b$ that Hydronomeas employs for each reservoir to form the parametric rule. Furthermore, Hydronomeas is using one parameter for each borehole to define a threshold of total storage over which no water is pumped from the aquifer. Therefore, Hydronomeas requires 10 parameters in total to parameterise the operation of the Athens water supply system.

It should be noted that the speed limitation, due to UWOT-Matlab interaction, does not allow to use the probability of failure as a metric in the objective function since this would require at least some dozens of 100 years runs hence very long optimisation times. Unfortunately, the average annual deficit, which is used instead in this study, is not a good measure for the reliability of a system because a zero value does not guaranty zero probability of failure. Likewise, a given value of average annual deficit does not correspond to a single value of probability of failure. Consequently, it is possible for the two models to suggest different management policies (corresponding to different probabilities of failure) despite estimating similar average 
annual deficit. For this reason, and in order to obtain comparable results of UWOT and Hydronomeas, the weighting factors of Hydronomeas objective function were kept fixed (equal to 10 and 0.01 for deficit and energy respectively) whereas a series of optimisations of UWOT with different weights were performed until results similar to those of Hydronomeas were achieved.

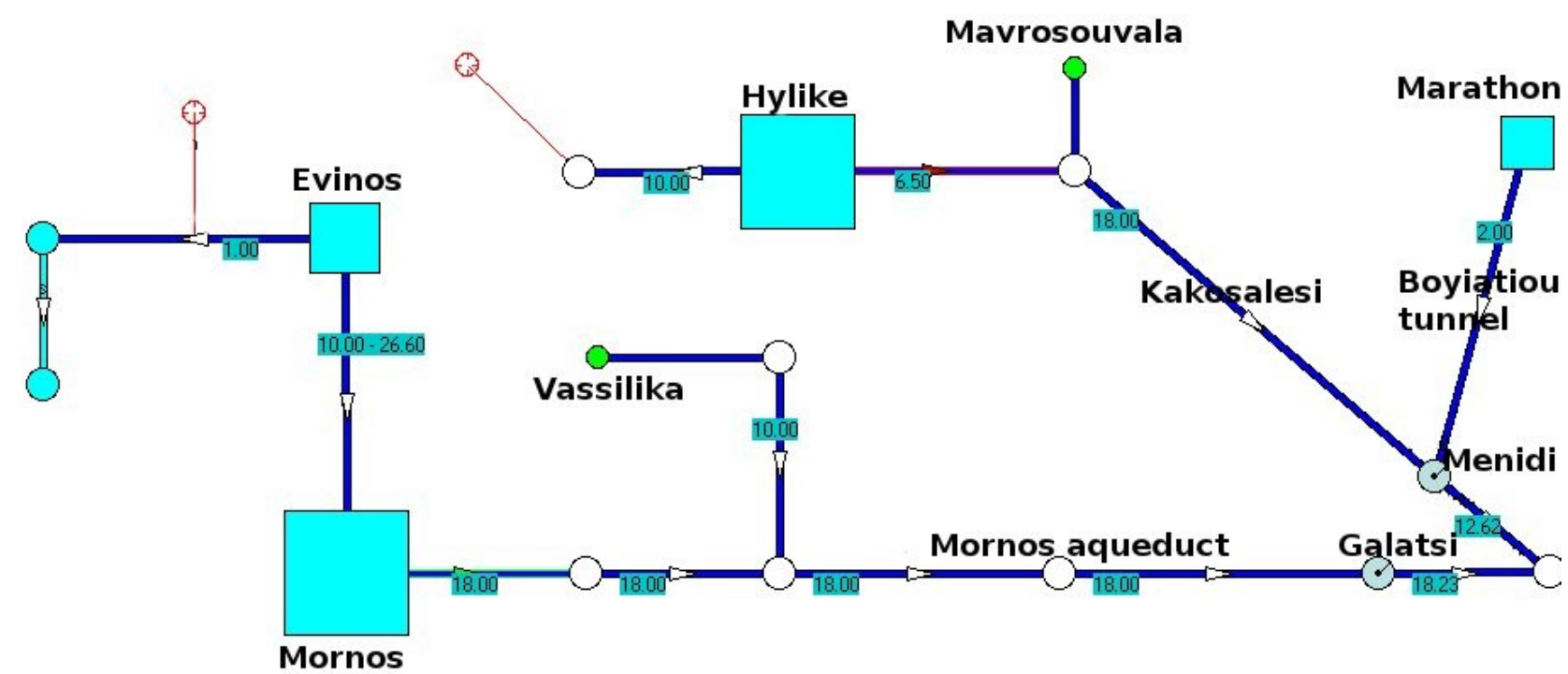

Figure 12: Representation of Athens external water supply system in Hydronomeas.

\section{Results}

Figure 13 displays the simulated and the historical water demand at the WTPs. These timeseries correspond to the demand signal at the input of the Menidi-Galatsi splitter (the rightmost component in Figure 8). The Nash-Sutcliffe coefficient is 0.910 . 


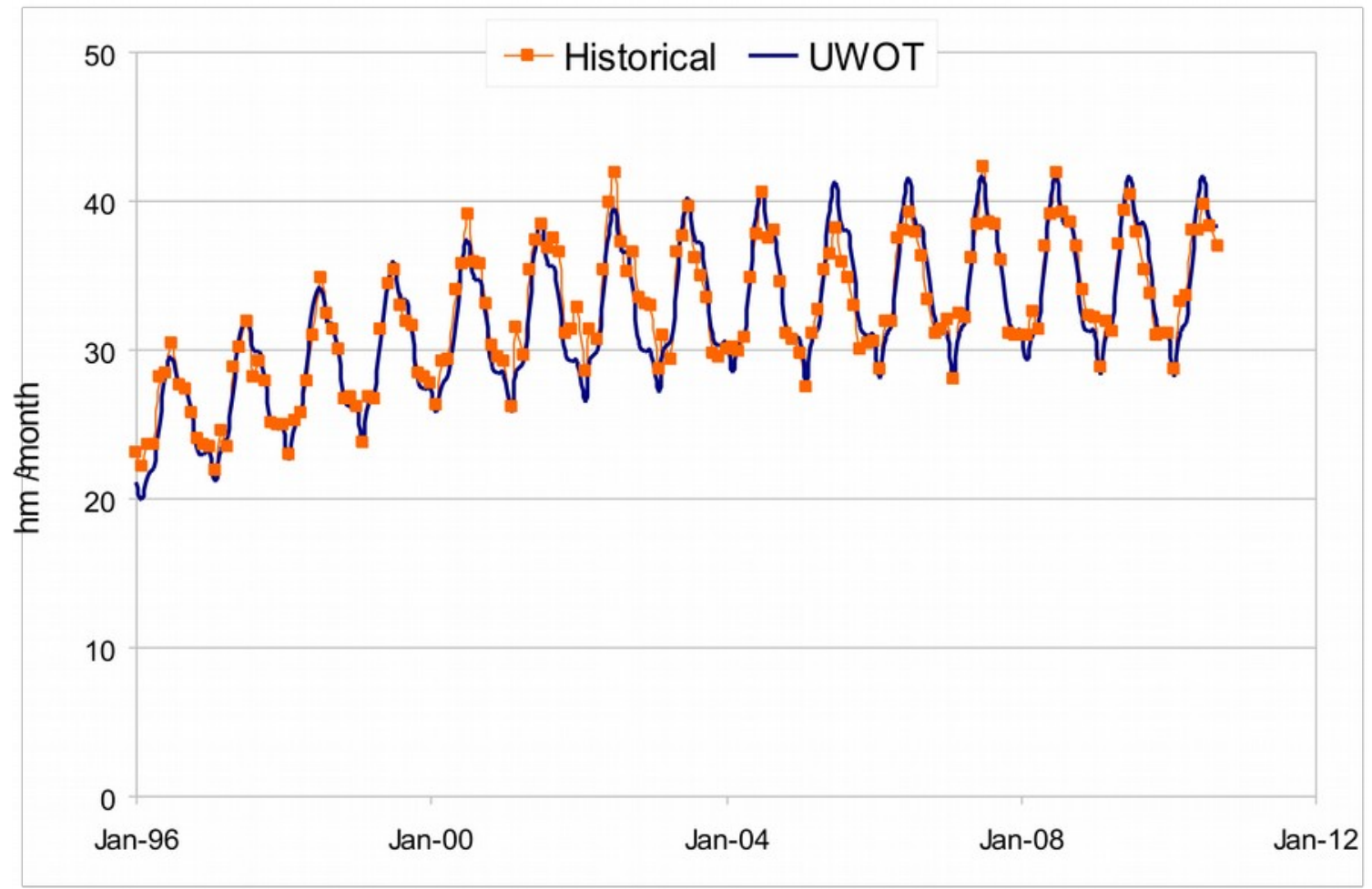

Figure 13: Historical versus simulated timeseries of water demand at the WTPs.

Figures $14 \mathrm{a}$ and $14 \mathrm{~b}$ display the fluctuation of Hylike storage and of Mornos plus Evinos storage with synthetic timeseries as simulated by UWOT and Hydronomeas. The dead volume of Hylike is $12 \mathrm{hm}^{3}$ and the dead volume of Mornos plus Evinos is $159 \mathrm{hm}^{3}$. The Nash-Sutcliffe coefficients are very high $(0.990$ for Hylike and 0.978 for Mornos)

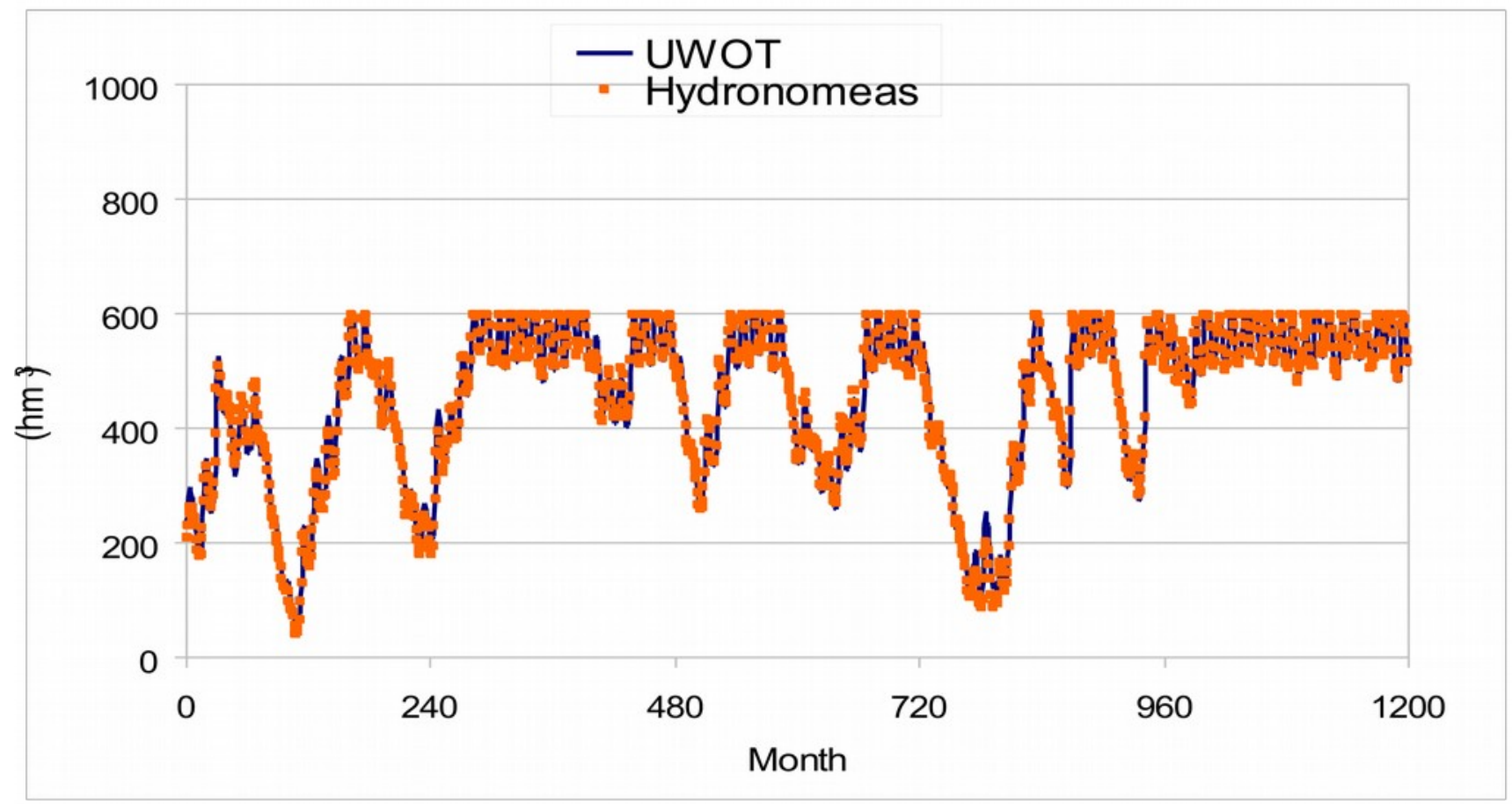


Figure 14a: Simulated fluctuation of Hylike storage with Hydronomeas and UWOT using synthetic timeseries.

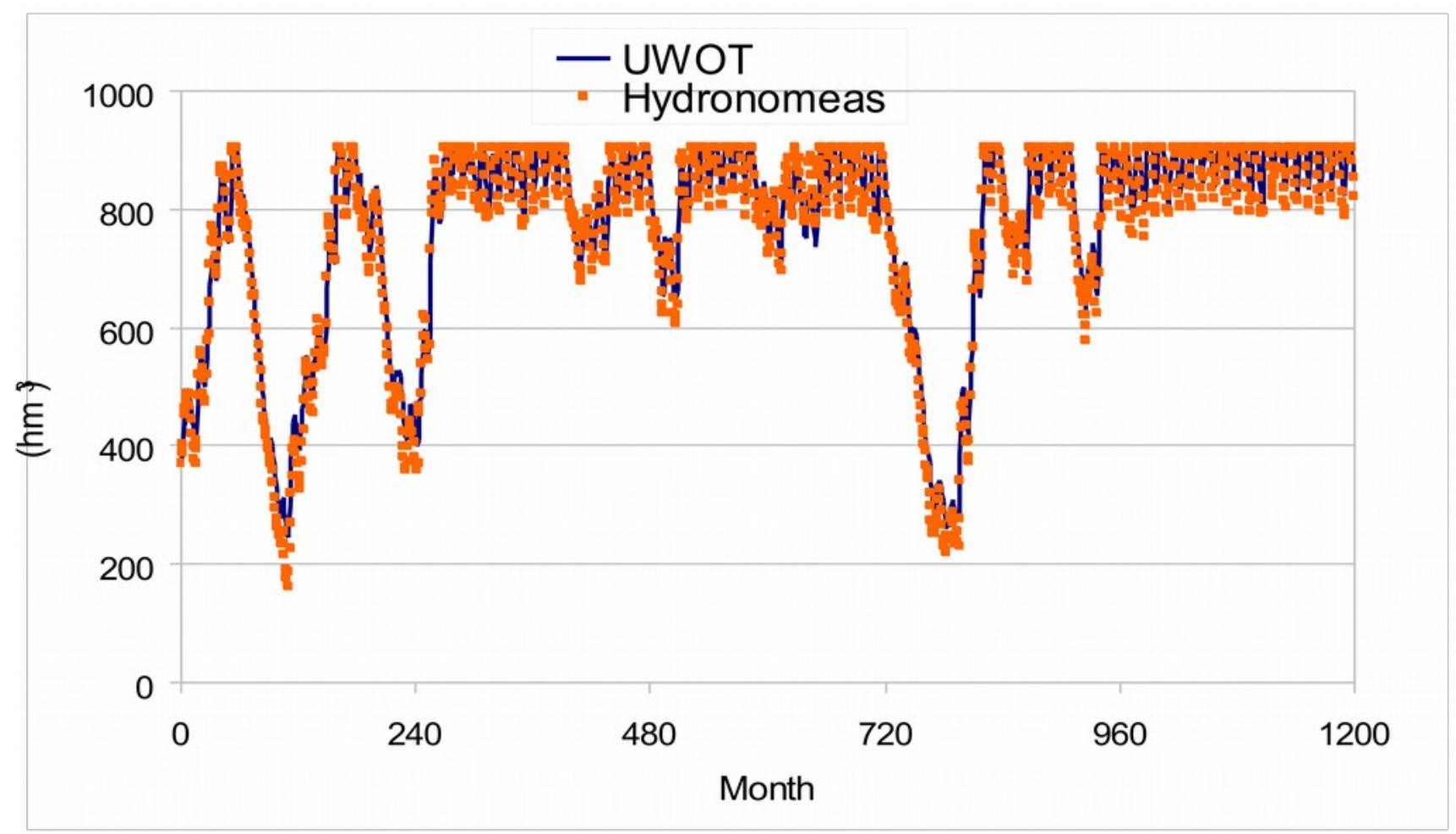

Figure 14b: Simulated fluctuation of Mornos plus Evinos storage with Hydronomeas and UWOT using synthetic timeseries.

The simulated total water storage reaches critically low values at two dates of the simulation with the synthetic timeseries (Figure 14b). The first one is in the $108^{\text {th }}$ month of the simulation and the second is in $793^{\text {rd }}$ month of the simulation. In the first date the simulated storage with Hydronomeas reached the minimum (dead volume) in all reservoirs.

Having completed the optimisations of both UWOT and Hydronomeas, the two models were run for the period 1996-2010, using historical timeseries, with the parameters found in their respective optimisation runs. Figures $15 \mathrm{a}$ and $15 \mathrm{~b}$ display the fluctuation of Hylike storage and of Mornos plus Evinos storage with historical timeseries as simulated by UWOT and Hydronomeas. The Nash-Sutcliffe coefficients of the storage timeseries simulated with UWOT against those simulated with Hydronomeas were 0.979 and 0.950 for the Hylike and Mornos respectively. It should be noted that the simulated storage cannot be compared against historical values of storage for the two reservoirs because the actual operation of the water supply system by EYDAP was different from that suggested by the two models. 


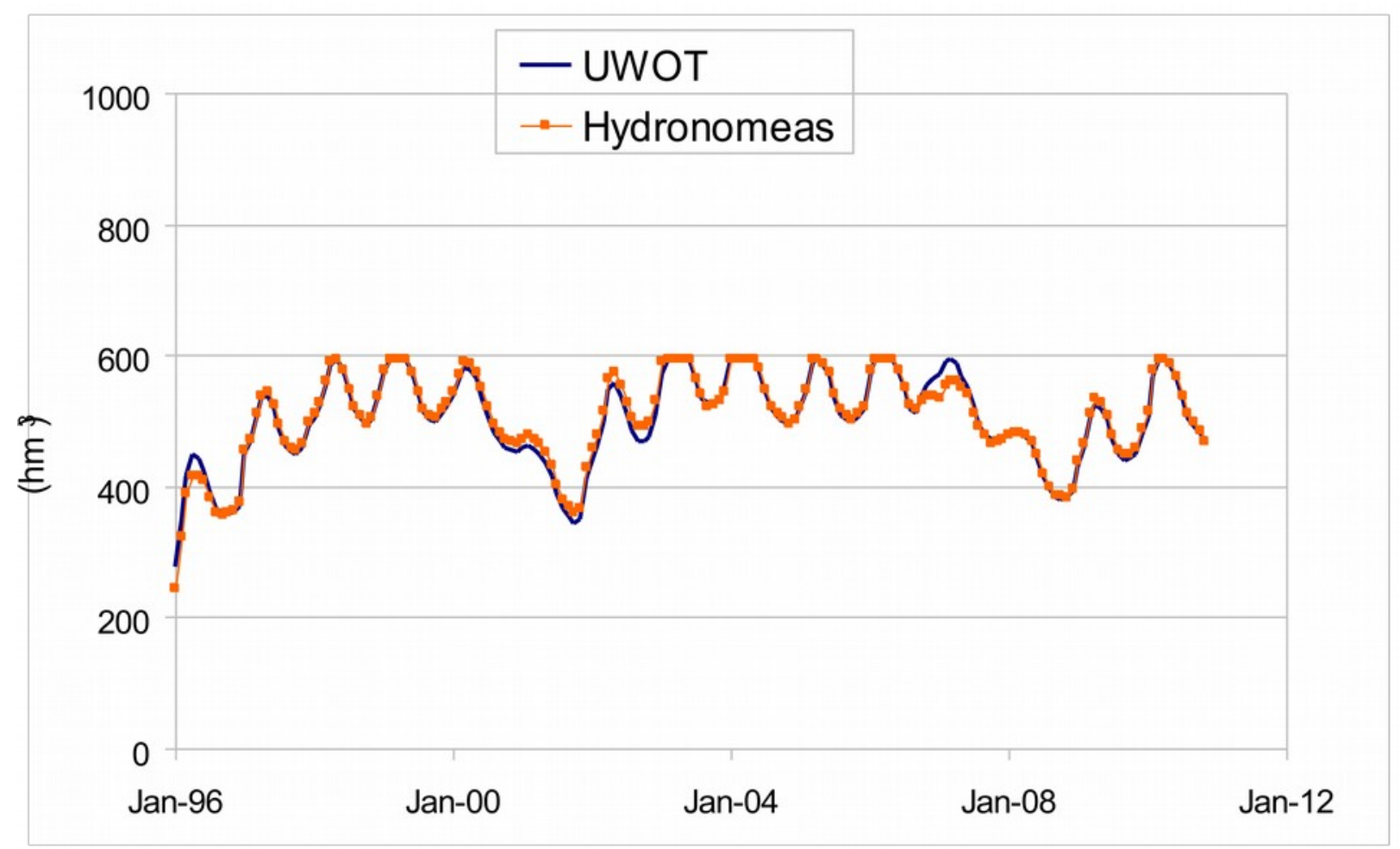

Figure 15a: Simulated fluctuation of Hylike storage with Hydronomeas and UWOT using historical timeseries.

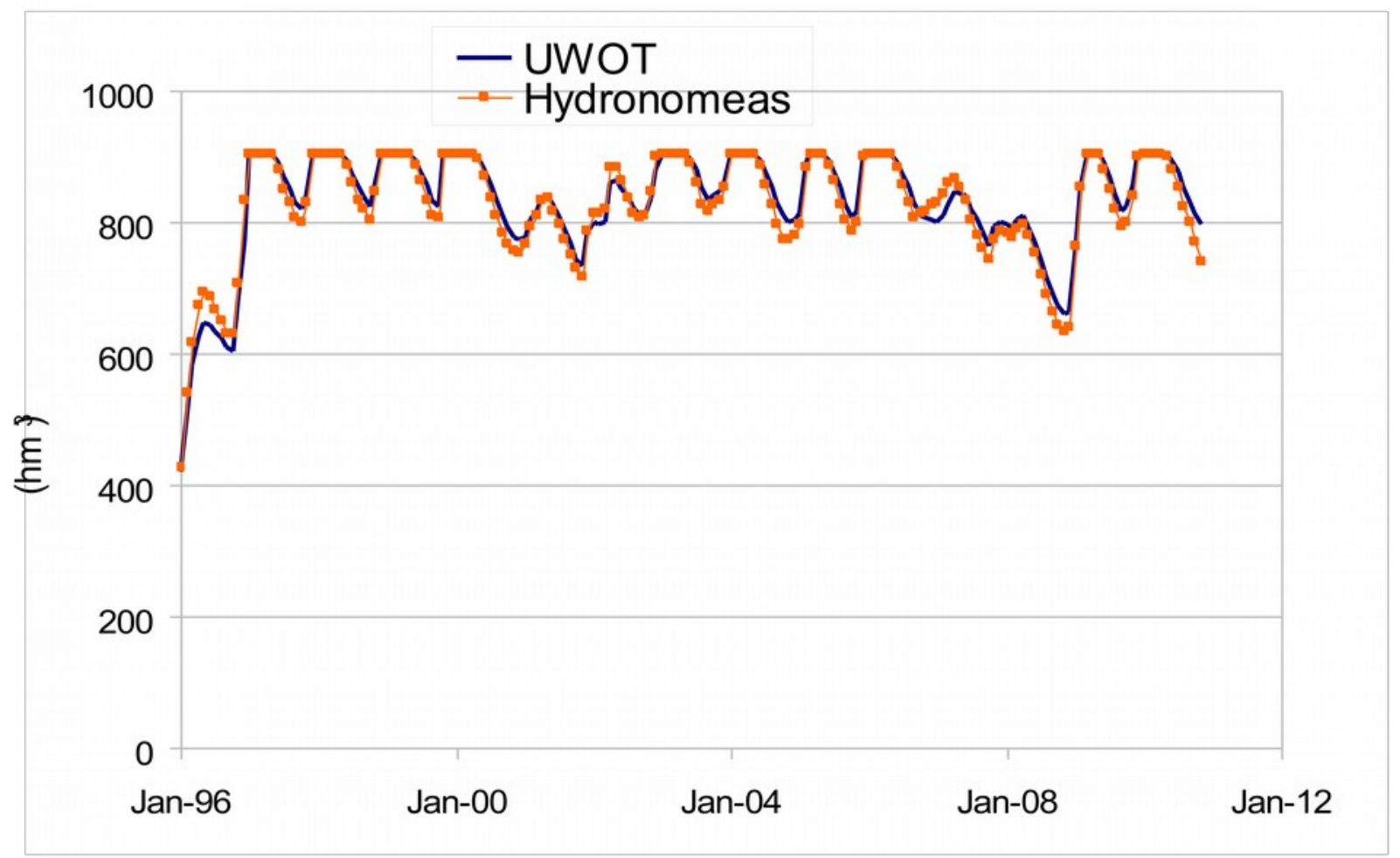

Figure 15b: Simulated fluctuation of Mornos plus Evinos storage with Hydronomeas and UWOT using historical timeseries.

Figure 16 displays the abstractions per month from the reservoirs of Hylike and Mornos according to Hydronomeas and UWOT simulation using historical timeseries. 

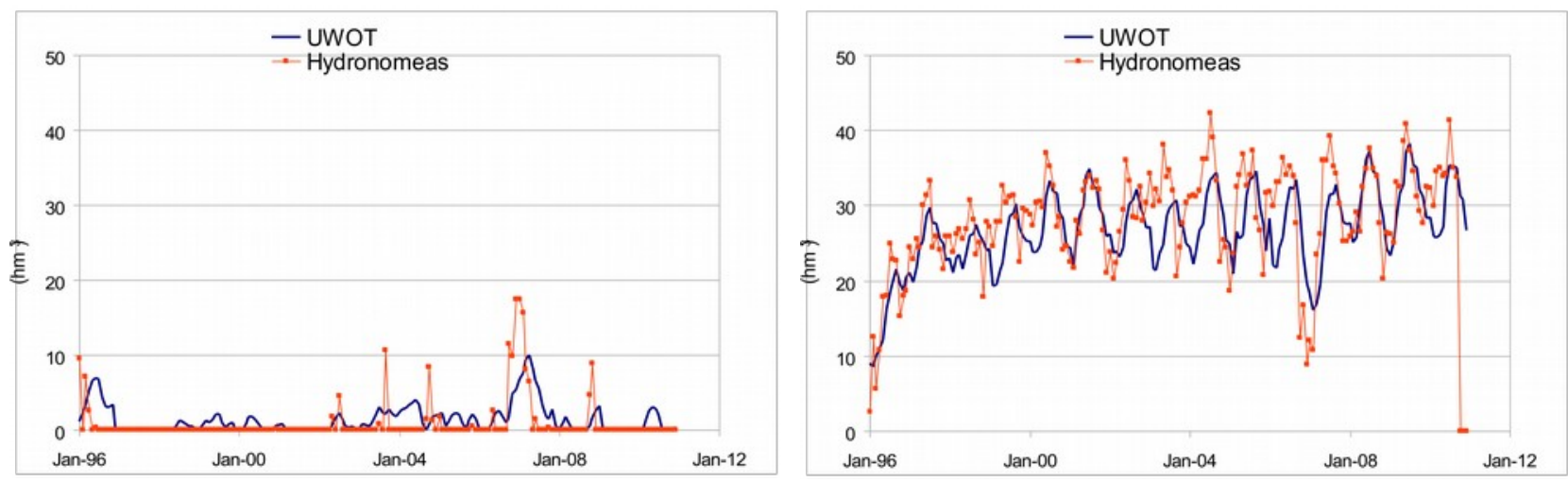

Figure 16: Abstractions per month from Hylike (left panel) and Mornos plus Evinos (right panel) estimated from simulation with Hydronomeas and UWOT using historical timeseries.

Figure 17 displays the groundwater abstractions per month from the boreholes of Mavrosouvala and Vassilika according to Hydronomeas and UWOT simulation using historical timeseries.
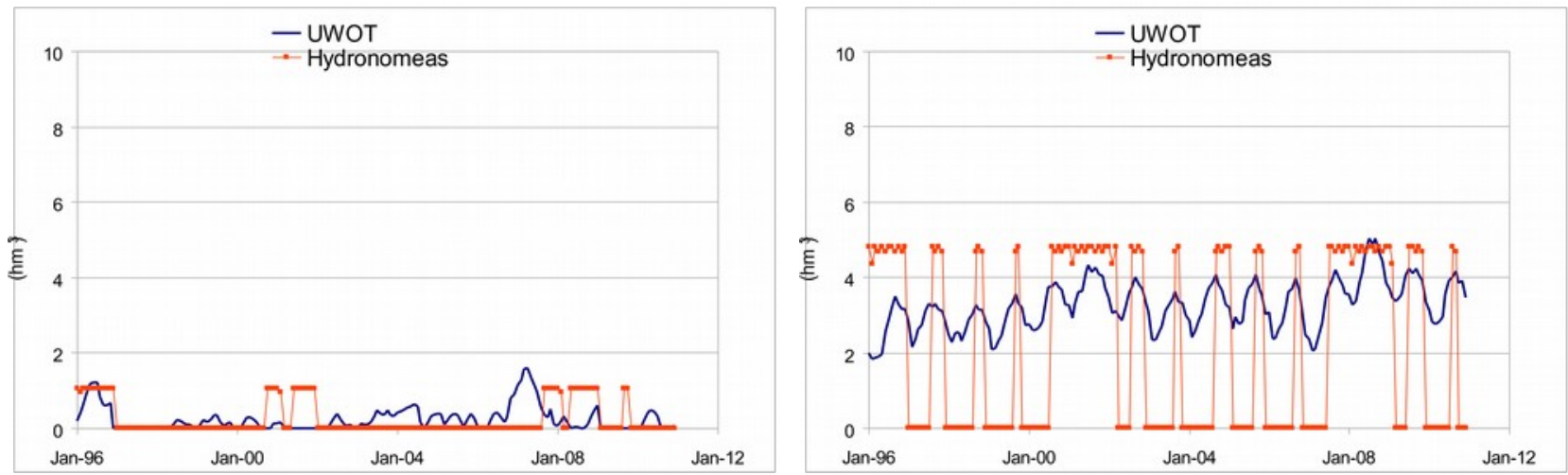

Figure 17: Abstractions per month from Mavrosouvala (left panel) and Vassilika (right panel) boreholes estimated from simulation with Hydronomeas and UWOT using historical timeseries.

The water balance for the simulation period with historical timeseries is shown in Table 2. The values in this table refer to average monthly values for the whole simulation period with historical timeseries. The first row gives the inflows due to runoff in the catchment area plus the direct rainfall on the reservoir minus any abstractions unrelated to water supply (e.g. irrigation and environmental flow). The second row gives the abstractions for the water supply. The numbers left and right of the slash correspond to UWOT and Hydronomeas values respectively. The third row gives the water losses from reservoirs due to infiltrations. The fourth row gives the spills from the reservoirs and the last row gives the difference between initial and final storage (positive values mean increased water storage). 
Table 2: Water balance of Athens external water supply system in $\mathrm{hm}^{3} / \mathrm{month}$ using UWOT and Hydronomeas.

\begin{tabular}{llllll}
\hline & Hylike & Evinos+Mornos & Marathon & Vassilika & Mavrosouvala \\
Rain+Runoff-Abstr. & 20.99 & 40.81 & 1.70 & & \\
To Athens & $1.26 / 0.90$ & $26.69 / 27.98$ & $1.58 / 1.62$ & $3.25 / 2.34$ & $0.24 / 0.24$ \\
Infiltration & $13.91 / 14.13$ & 0 & 0 & & \\
Spill & $4.39 / 4.58$ & $12.06 / 11.14$ & $0.24 / 0.07$ & & \\
Storage difference & $1.25 / 1.36$ & $2.28 / 1.71$ & $0.11 / 0.00$ & & \\
\hline
\end{tabular}

The energy consumed for the abstraction of water from boreholes and from Hylike reservoir according to UWOT and Hydronomeas is given in Table 3.

Table 3: Total energy consumption in GWh according to UWOT and Hydronomeas for the historical period.

\begin{tabular}{ll}
\hline Hylike & $102.46 / 72.66$ \\
Mavrosouvala & $65.06 / 66.42$ \\
Vassilika & $134.72 / 66.42$ \\
Total & $302.23 / 235.99$ \\
\hline
\end{tabular}

\section{Discussion}

Figure 13 indicates a good fit between the historical demand and the demand estimated by UWOT. This verifies the plausibility of the assumptions used to reconstruct the monthly timeseries of population and frequency-of-use. Of course, the approach used in this study is not appropriate for demand forecasting. This would require a more sophisticated methodology like the use of a system dynamics model and/or the use of agent based modelling to estimate how the frequency-of-use changes with social attitudes (e.g. public awareness) coupled with UWOT to estimate the demand. Early work on this is discussed in Koutiva and Makropoulos (2012) and Baki et al. (2012).

The good fit of the simulated storage in Figures 14a-b and Figures 15a-b and the high Nash-Sutcliffe values indicate that the assumptions used to reduce the number of optimised parameters were reasonable. A sensitivity analysis was performed concerning the optimised parameters using a Matlab algorithm (Ekström, 2005) which is based on the Morris method (Morris, 1991). Morris proposed an effective screening sensitivity measure to identify the few important factors in models with many factors. This method overcomes the disadvantages of local methods (Saltelli and Annoni, 2010), which examine parameters one at a time. The average values of the elementary effects of the five parameters in $\mathbf{C M}$ matrix (Table 1) and the four in vector $\boldsymbol{a}$ are: $1.55,0.46,0.18,0.78,0.18,2.08,0.94,0.84,1.99$. Therefore the ranking of the parameters $c_{1}$ to $c_{9}$ in order of importance is $c_{6}, c_{9}, c_{1}, c_{7}, c_{8}, c_{4}, c_{2}, c_{3}$ and $c_{5}$.

The result of the two models are slightly different with UWOT's management policy being more on the safe side since the storage of Evinos plus Mornos does not fall bellow the line of $200 \mathrm{hm}^{3}$ as it happens with the storage simulated by Hydronomeas in Figure 14b. Of course, this more cautious management comes with the increased energy consumption shown in Table 3. The slight differences in the results of the two models should be attributed to the different conceptualisation and implementation of the parameterisation-simulation-optimisation method. More specifically, UWOT relates the abstractions from the reservoirs to storage whereas Hydronomeas first identifies the target storage of each reservoir and then 
attempts to achieve it by triggering abstractions each time the storage in a reservoir exceeds the optimum value. This gives the characteristic pulses displayed in Figure 16 and Figure 17. On the contrary, UWOT abstractions are continuous and with a smooth variation (related to the variation of storage inside reservoirs), and have characteristics similar to that of a traditional human-driven operation.

It should be noted that a thorough assessment of two models would require a multi-objective approach. These would result in two Pareto Fronts, one for each model, of which the comparison would give a clear picture about the performance of these two models.

Although UWOT optimised successfully the operation of the external hydrosystem, even resulting in more realistic suggestions compared to the actual operational tool used by the Athens Water Company, it has two key disadvantages that have to be pointed out: (a) UWOT was significantly slower that Hydronomeas (up to five times slower in simulation mode and even slower in optimisation mode). This is mainly attributed to the sequential calls of the MEX engine by Matlab for each time step of each simulation and (b) the parameterisation of a hydrosystem in UWOT depends on network complexity. For example, Figure 18 displays the representation of a hydrosystem with one loop in Hydronomeas and in UWOT. The water released from the lower reservoir can be supplied to the location of demand (T12 in Hydronomeas, component IN in UWOT) via two alternative routes. To represent this in UWOT, an extra splitter (hence an extra parameter) is required, whereas Hydronomeas parameterisation depends only on the number of reservoirs regardless of the network schema.
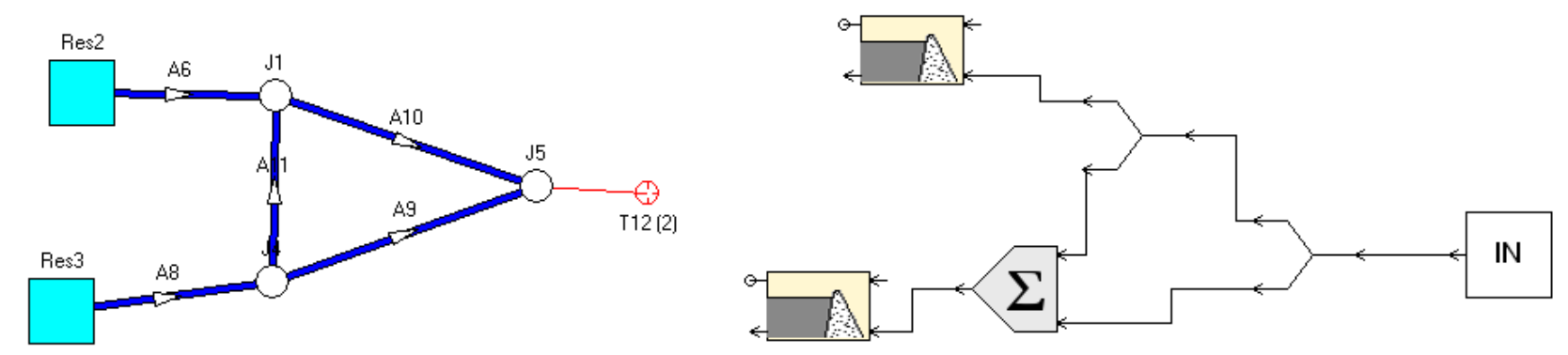

Figure 18: Representation of a loop in Hydronomeas (left) and UWOT (right).

Still, the similarity in the results obtained by the two models is very positive for UWOT, suggesting that UWOT is indeed a reliable tool able to optimise water supply system operations even for systems as complex as Athens. This clearly comes with the significant advantage over Hydronomeas and other similar tools of being able to also model demand generation and hence provide a solution for the simulation of the complete urban water cycle, from source-to-tap. Issues of speed of computation are being addressed with a standalone version of UWOT, not linked to Matlab, which is currently under development. This will allow to estimate the probability of various components of the urban water cycle to fail to respond to their duty (reservoirs fail to supply water, aqueducts fail to transfer, treatment plants fail to treat the required amount). Afterwards, this probability of failure could be translated to risk of failure provided a table of consequences for each type of failure is available 


\section{Conclusions}

This study presented the development of UWOT, a model capable of simulating the complete urban water cycle, and its application to the Athens water system. UWOT is different from other urban water cycle models because it employs a demand-oriented approach, based on the simulation of demand "signals" emitted and received by the network components instead of simulating the water flows between them. The tool can be easily customised through a CAD-like user interface and allows for the definition and analysis of urban water networks of arbitrary topology. In previous studies (Rozos and Makropoulos, 2012; Rozos et al., 2010) an earlier version of UWOT has been used to optimise the components of the internal water supply system, with an emphasis on rainwater harvesting and grey water recycling. In this study, the operation of the particularly complex external water supply system of Athens was optimised using a parameterisation-simulation-optimisation (PSO) approach. To test its performance, UWOT was compared to the operational tool currently used by the Water Company of Athens with encouraging results. It is therefore suggested that UWOT can successfully be used to simulate and optimise the complete urban water cycle from source to tap and back again, from the water supply source, through the households, all the way to the disposal of stormwater and wastewater to water bodies. This potential makes it an ideal tool for integrated demand and supply management studies, directly supporting both centralised and distributed water management solutions.

\section{Acknowledgments}

This work was supported by TRUST (TRansitions to the Urban Water Services of Tomorrow) research project.

\section{References}

Baki, S., Koutiva I. and C. Makropoulos (2012). A hybrid artificial intelligence modelling framework for the simulation of the complete, socio-technical, urban water system. 6th International Congress on Environmental Modelling and Software - iEMSs 2012, 1-5 July 2012, Leipzig Germany

Butler, D., and Memon, F. (2006). Water demand management, IWA Publishing, London, March 2006.

Castalia (2012), A computer system for stochastic simulation and forecasting of hydrologic processes, available online at http://itia.ntua.gr/en/softinfo/2/, accessed at 12/01/2012.

Directive 2000/60/EC, available online at eur-lex.europa.eu/LexUriServ/LexUriServ.do? uri=CELEX:32000L0060:EN:NOT, accessed at 14/12/2011.

Duan, Q., Sorooshian, S., Gupta, V. (1992). Effective and efficient global optimization for conceptual rainfall-runoff models. Water Resources Research 28 (4), 1015-1031.

EEA. (2001). Sustainable water use in Europe: Part 2 - Demand management, Environmental issue report no. 19, C European Environment Agency, Copenhagen, 2001.

Efstratiadis, A., Karavokiros, G., and Mamassis, N. (2009). Master plan of the Athens water resource system 
- Year 2009, Maintenance, upgrading and extension of the Decision Support System for the management of the Athens water resource system, Report 1, 116 pages, Department of Water Resources and Environmental Engineering - National Technical University of Athens, Athens, April 2009.

Efstratiadis, A., Koutsoyiannis, D., and Xenos, D. (2004). Minimising water cost in the water resource management of Athens, Urban Water Journal, 1 (1), pp. 3-15.

Ekström, P-A., 2005, A Simulation Toolbox for Sensitivity Analysis, Masters Degree Project, Faculty of Science and Technology, Uppsala Universitet.

ELSTAT. (2012). Hellenic Statistical Authority, Housing census, Buildings, available online at http://www.statistics.gr/portal/page/portal/ESYE/PAGE-database, accessed at 24/02/2012.

EYDAP. (2012). Water Treatment Plants available online at www.eydap.gr/index.asp?a_id=297, accessed at $12 / 01 / 2012$.

Grant, N. (2006). Water conservation products, In Water Demand Management, Butler, D. and Memon, F. A. (Eds.), IWA Publishing, London, pp. 82 - 106.

Goldsim (2011), Monte Carlo Simulation Software for Decision and Risk Analysis, available online at www.goldsim.com, accessed at 14/12/2011.

Gualtieri, C. (2011). Urban Hydroinformatics. Data, Models and Decision Support for Integrated Urban Water Management, Environmental Modelling and Software, 26 9, September 2011, pp. 1158-1159.

Hydronomeas, (2012), available online at http://itia.ntua.gr/el/softinfo/4/, accessed 12/01/2012.

Katerinopoulou, A., Kagia, K., Karapiperi, M., Kassela, A. Paschalis, A., Tsarouchi, G.-M., Markonis, Y. , Papalexiou, S.M., and Koutsoyiannis, D. (2009). Reservoir yield-reliability relationship and frequency of multi-year droughts for scaling and non-scaling reservoir inflows, European Geosciences Union General Assembly 2009, Geophysical Research Abstracts, Vol. 11, Vienna, 8063, European Geosciences Union.

Kozanis, S., Christofides, A., Efstratiadis, A., Koukouvinos, A., Karavokiros, G., Mamassis, N., Koutsoyiannis, D., and Nikolopoulos. D. (2012), Using open source software for the supervision and management of the water resources system of Athens, European Geosciences Union General Assembly 2012, Geophysical Research Abstracts, Vol. 14, Vienna, 7158, European Geosciences Union.

Koutiva I. and C. Makropoulos (2012) Linking tools for social simulation and urban water network modelling for supporting an adaptive approach of urban water resources management, 6th International Congress on Environmental Modelling and Software - iEMSs 2012, 1-5 July 2012, Leipzig Germany.

Koutsoyiannis, D., and, Economou, A. (2003), Evaluation of the parameterization-simulation-optimization approach for the control of reservoir systems, Water Resources Research, 39 (6), pp. 1170-1176, doi:10.1029/2003WR002148.

Koutsoyiannis, D., Efstratiadis, A., and Karavokiros, G. (2002). A decision support tool for the management of multi-reservoir systems, Journal of the American Water Resources Association, 38 (4), 945-958.

Koutsoyiannis, D. (2001). Coupling stochastic models of different time scales, Water Resources Research, 37 
(2), 379-392.

Kyoto Protocol, available online at unfccc.int/kyoto_protocol/items/2830.php, accessed 14/12/2011.

Makropoulos, C. K. and D. Butler (2010). Distributed Water Infrastructure for Sustainable Communities, Water Resources Management 24(11): 2795-2816

Makropoulos, C. K., Natsis, K., Liu, S., Mittas, K., and Butler, D. (2008). Decision Support for Sustainable Option Selection in Integrated Urban Water Management, Environmental Modelling and Software, 23, 12, pp. 1448-1460.

Mamassis, N., Efstratiadis, A., Karavokiros, G., Kozanis, S., and Koukouvinos, A. (2011). Maintenance, upgrading and extension of the Decision Support System for the management of the Athens water resource system, Final Report, 84 pages, Department of Water Resources and Environmental Engineering - National Technical University of Athens.

MathWorks (2011) Product Support, MEX-files Guide, available online at www.mathworks.com, accessed at $22 / 12 / 2011$.

Minx, J., Creutzig, F., Medinger, V., Ziegler, T., Owen, A., Baiocchi, G. (2010). DEVELOPING A PRAGMATIC APPROACH TO ASSESS URBAN METABOLISM IN EUROPE, A Report to the European Environment Agency, Stockholm Environment Institute.

Mitchell, V.G., Mein, R.G., and McMahon, T.A. (2001). Modelling the urban water cycle. Journal of Environmental Modelling and Software, 16 7,pp. 615-629.

Mitchell V.G.. (2005). Aquacycle User Guide, aquacycle a daily urban water balance model, revision 1.2.1, February 2005.

Morris, M.D., 1991. Factorial sampling plans for preliminary computational experiments. Technometrics 33, pp. 161-174.

Last, E., and Mackay, R. (2010). City Water Balance - A New Tool For Scoping Integrated Urban Water Management Options, IAHR European Congress, 2010.

Nalbantis, I., and Koutsoyiannis, D. (1997). A parametric rule for planning and management of multiple reservoir systems, Water Resources Research, 33 (9), pp. 2165-2177.

Niza, S., Rosado, L., and Ferro, P. (2009). Urban Metabolism: Methodological Advances in Urban Material Flow Accounting Based on the Lisbon Case Study, Journal of Industrial Ecology, 13(3), DOI: 10.1111/j.1530-9290.2009.00130.x, pp. 384-405.

Papoulis, A. (1999), Probability and Statistics, Prentice-Hall International, Inc., Englewood Cli s, NJ., pp. 403-404.

ReVelle, C. (1999). Optimizing Reservoir Resources - Including a New Model for Reservoir Reliability, John Wiley, New York, 1999.

RIBASIM (2012), River Basin Planning and Management, http://www.wldelft.nl/soft/ribasim/int/index.html, accessed 15/3/2012.

Rozos, E., and C. Makropoulos. (2012). Assessing the combined benefits of water recycling technologies by modelling the total urban water cycle, Urban Water Journal, 9(1), doi:10.1080/1573062X.2011.630096. 
Rozos, E., Baki, S., Bouziotas, D., and Makropoulos, C. (2011). Exploring the link between urban development and water demand: The impact of water-aware technologies and options, Computing and Control for the Water Industry (CCWI) 2011, Exeter, UK, CCWI2011-311, University of Exeter.

Rozos, E., Makropoulos, C., and Butler, D.(2010). Design robustness of local water-recycling schemes, Journal of Water Resources Planning and Management - ASCE, 136 (5), 531-538, doi:/10.1061/ (ASCE)WR.19, 2010.

Saltelli, A., and Annoni, P. (2010). How to avoid a perfunctory sensitivity analysis. Environmental Modelling and Software, 25, pp. 1508-1517.

Sydney water (2011), Water efficiency program, available online at www.sydneywater.com.au/Water4Life/, accessed 14/12/2011.

Su, S., Deininger, R. (1972). Generalization of White's method of successive approximations to periodic Markovian decision processes. Operations Research, 20 (2), pp. 318-326.

TRUST (2012). TRansitions to the Urban Water Services of Tomorrow, available online at http://www.trust-i.net/, accessed at August 2012.

Venkatesh, G., and Brattebø, H. (2011). Energy consumption, costs and environmental impacts for urban water cycle services: Case study of Oslo (Norway), Energy, 36 (2011), pp. 792-800.

Vieira, J., M. C. Cunha, L. Nunes, J.P. Monteiro, L. Ribeiro, T. Stigter, J.Nascimento, and H. Lucas (2011) Optimization of the Operation of Large-Scale Multisource Water-Supply Systems, J. Water Resour. Plann. Manage. 137, 150. 